\title{
Rab11 and Its Effector Rab Coupling Protein Contribute to the Trafficking of $\beta 1$ Integrins during Axon Growth in Adult Dorsal Root Ganglion Neurons and PC12 Cells
}

\author{
Richard Eva, ${ }^{1}$ Elisa Dassie, ${ }^{1}$ Patrick T. Caswell, ${ }^{2}$ Gunnar Dick, ${ }^{1}$ Charles ffrench-Constant, ${ }^{3}$ Jim C. Norman, ${ }^{2}$ \\ and James W. Fawcett ${ }^{1}$ \\ ${ }^{1}$ Cambridge Centre for Brain Repair, Department of Clinical Neurosciences, University of Cambridge, Cambridge CB2 2PY, United Kingdom, ${ }^{2}$ Beatson \\ Institute for Cancer Research, Bearsden, Glasgow G61 1BD, United Kingdom, and ${ }^{3}$ Medical Research Council Centre for Regenerative Medicine, Centre for \\ Multiple Sclerosis Research, University of Edinburgh, Queen's Medical Research Institute, Edinburgh EH16 4TJ, United Kingdom
}

Integrins play an important part in axon growth, but integrin traffic in neurons is poorly understood. Expression of the tenascin-Cbinding integrin $\alpha 9$ promotes axon regeneration. We have therefore studied the mechanism by which $\alpha 9$ integrin and its partner $\beta 1$ are trafficked along axons and at the growth cone using adult DRG neurons and PC12 cells. We have focused on the small GTPase Rab11 and its effector Rab coupling protein (RCP), as they are involved in the long-range trafficking of $\beta 1$ integrins in other cells. Rab11 colocalizes with $\alpha 9$ and other $\alpha$ integrins and with $\beta 1$ integrin in growth cones and axons, and immunopurified Rab11 vesicles contain $\alpha 9$ and $\beta 1$. Endocytosed $\beta 1$ integrins traffic via Rab11. However, Rab11 vesicles in axons are generally static, and $\alpha 9$ integrins undergo bouts of movement during which they leave the Rab11 compartment. In growth cones, $\alpha 9$ and $\beta 1$ overlap with RCP, particularly at the growth cone periphery. We show that $\beta 1$ integrin trafficking during neurite outgrowth involves Rab11 and RCP, and that manipulation of these molecules alters surface integrin levels and axon growth, and can be used to enhance $\alpha 9$ integrin-dependent neurite outgrowth. Our data suggest that manipulation of trafficking via Rab11 and RCP could be a useful strategy for promoting integrin-dependent axonal regeneration.

\section{Introduction}

Integrins are a large family of transmembrane heterodimeric receptors for extracellular matrix proteins. They consist of an $\alpha$ and a $\beta$ subunit that mediate numerous cellular functions including adhesion, proliferation, migration, synaptic plasticity, neurite outgrowth, and peripheral nerve regeneration (Pozzi et al., 1998; Werner et al., 2000; Brakebusch and Fässler, 2005; Gardiner et al., 2005, 2007; Webb et al., 2007; Cingolani et al., 2008; Plantman et al., 2008; Moser et al., 2009). We recently expressed the tenascinbinding integrin $\alpha 9$ in sensory neurons with the intention of promoting regeneration of their axons in the damaged spinal cord (Andrews et al., 2009). $\alpha 9$ expression stimulated profuse axon growth on tenascin and various inhibitory molecules in vitro, but regeneration in the spinal cord was modest. The difference between growth in vitro and in vivo could have been because of the many inhibitory molecules in the damaged CNS, but some of these can be overcome in vitro by integrin activation ( $\mathrm{Hu}$ and

Received May 12, 2010; revised July 7, 2010; accepted July 9, 2010.

This work was supported by grants from the Medical Research Council, The Wellcome Trust, the Engineering and Physical Sciences Research Council, The Christopher and Dana Reeve Foundation, The Henry Smith Charity, European Union's Sixth Framework Programme NeuroNE, European Union's Seventh Framework Programmes PLASTICISE and Spinal Cord Repair, and The John and Lucille Van Geest Foundation. We thank Aviva Tolkovsky for critical reading of this manuscript.

Correspondence should be addressed to James W. Fawcett, Cambridge Centre for Brain Repair, Department of Clinical Neurosciences, University of Cambridge, Robinson Way, Cambridge CB2 2PY, UK. E-mail: jf108@cam.ac.uk. DOI:10.1523/JNEUROSCI.2425-10.2010

Copyright $\odot 2010$ the authors $\quad 0270-6474 / 10 / 3011654-16 \$ 15.00 / 0$
Strittmatter, 2008), and we have recently found that $\alpha 9$ integrin is not transported efficiently into CNS axons (M. R. Andrews, E. Franssen, E. R. Heintz, and J. W. Fawcett, unpublished observations). We therefore hypothesized that integrin activation and/or transport may be defective in the damaged CNS. Currently, there is limited information about the mechanism of neuronal integrin traffic; however, in non-neuronal cells, it is evident that a key pathway of integrin trafficking is regulated by the small GTPase Rab11 (Powelka et al., 2004; Fabbri et al., 2005; Skalski and Coppolino, 2005; Yoon et al., 2005; Pellinen and Ivaska, 2006; Caswell et al., 2008). Rab11 is a regulator of membrane protein transport from recycling endosomes to the plasma membrane (Ullrich et al., 1996; Sönnichsen et al., 2000). A number of studies have identified a role for Rab11 in the transport of other surface molecules in neurons, where it regulates the traffic of AMPA receptors in dendrites during long-term potentiation (Park et al., 2004; Lisé et al., 2006; Brown et al., 2007; Choe et al., 2007; Correia et al., 2008; Wang et al., 2008), and axonal trafficking of Trk receptors (Ascaño et al., 2009), adding to the evidence that recycling endosomes contribute to the trafficking of membrane proteins into axons (Kamiguchi, 2003; Winckler, 2004; Allen and Chilton, 2009).

We set out to investigate whether Rab11 contributes to the axon/growth cone trafficking of integrins during neurite outgrowth, focusing on $\alpha 9$ integrin and its binding partner $\beta 1$, using PNS neurons that express several integrins (Gardiner et al., 2005, 2007). We provide evidence that $\alpha 9$ and $\beta 1$ integrins traffic 
through a Rab11 domain in adult dorsal root ganglion (DRG) neurons and differentiated PC12 cells and that endocytosed integrins are anterogradely transported. We also describe a role for the Rab11 effector Rab coupling protein (RCP) and show that its overexpression increases $\beta 1$ integrin expression at the surface of DRG growth cones and differentiated PC12 cells. Furthermore, we show that $\alpha 9$ integrin-dependent neurite outgrowth can be enhanced in vitro by overexpression of either Rab11 or RCP.

\section{Materials and Methods}

\section{DNA constructs}

Integrin $\alpha 9$ enhanced green fluorescent protein (EGFP)-N3 was obtained from Addgene, deposited by Dean Sheppard (University of California, San Francisco, San Francisco, CA). Integrin $\alpha 5$ EGFP-N3 was originally a gift from Donna Web in the laboratory of Rick Horwitz (University of Virginia, Charlottesville, VA) and has been previously described (Laukaitis et al., 2001). cDNA encoding human Rab1la was amplified by PCR introducing HindIII and BamHI restriction sites, and cloned into EGFP-C2. EGFP was excised from this vector and replaced with the mCherry cDNA (with AgeI and XhoI sites introduced by PCR). RCP constructs were originally from the laboratory of Mary McCaffrey (University College Cork, Cork, Ireland). pEGFP-C3 RCP has been previously described (Damiani et al., 2004), as has pEGFP-C3 RCP I621E (Lindsay and McCaffrey, 2004).

Immunofluorescence reagents and antibodies for Western blotting Antibodies against Rab11 were obtained from Zymed (Invitrogen) and used at 1:50. Untagged human $\alpha 9$ integrin was detected with anti- $\alpha 9 \beta 1$ clone Y9A2 (Abcam) at 1:200 (for live labeling, or after methanol fixation). Directly conjugated Alexa Fluor 488 or 647 anti-mouse/rat CD29 (integrin $\beta 1$ ) antibody (clone HM $\beta 1-1$ ) was used to detect $\beta 1$ integrin at a concentration of 1:100. Anti- $\beta$-tubulin class III (TUJ1) (SigmaAldrich) was used at 1:400. Anti- $\alpha 3$ integrin (clone Ralph 3.2) was obtained from Santa Cruz Biotechnology and used at 1:500. Secondary antibodies were Alexa conjugates from Invitrogen used at 1:800. $\beta 1$ integrin was detected on Western blots using the antibody AB1952 (Millipore), and $\beta$-actin was detected using the antibody AC-15 (Abcam). ARF6 was detected with monoclonal anti-ARF6 (ARFAG clone) (Abcam), Rab5 with polyclonal anti-Rab5 (Abcam), calnexin with anti-calnexin clone H-70 (Santa Cruz), KDEL with anti-KDEL clone 10C3 (Abcam), and GM130 with polyclonal anti-GM130 (BD Biosciences Transduction Laboratories). Purified rabbit IgG was from Sigma-Aldrich.

Secondary antibodies were HRP conjugates from GE Healthcare. $\alpha 9$ integrin was detected on Western blots using a chicken polyclonal integrin $\alpha 9$ antibody (Abcam) and HRP-conjugated anti-chicken (Millipore).

\section{PC12 cell culture}

Low passage number PC12 cells were acquired from the European Collection of Cell Cultures (ECACC) and routinely grown in RPMI 1640 media (Sigma-Aldrich) supplemented with $10 \%$ batch-tested French FBS (Biosera), 1\% penicillin/streptomycin, and $2 \mathrm{~mm}$ L-glutamine on flasks coated with type IV collagen (Sigma-Aldrich), according to ECACC guidelines.

\section{Generation of stable PC12 cell lines expressing green fluorescent protein-tagged constructs}

PC12 cells were transfected with plasmid DNA using Lipofectamine 2000 (Invitrogen) on $90 \mathrm{~mm}$ Petri dishes and grown in the usual media plus $400 \mu \mathrm{g} / \mathrm{ml}$ neomycin (G418; Invitrogen). Both clonal and nonclonal lines were generated. To generate clonal lines, cultures wells were left in selective media until isolated colonies were visible. These were screened for green fluorescent protein (GFP) expression and isolated using sterile glass cloning rings and expanded in selective culture media. Nonclonal lines were generated by growing mixed cultures from colonies not selected for isolation. Observations of stable cell lines were made using several clonal lines and mixed nonclonal cultures to ensure against arti- facts of clonal expression. Individual clonal lines were then selected for repeated experiments.

\section{Generation of a stable PC12 cell line expressing untagged $\alpha 9$ integrin}

PC12 cells were transduced with retroviral $\alpha 9$ integrin in the presence of polybrene $(4 \mu \mathrm{g} / \mathrm{ml})$ and performed overnight at $37^{\circ} \mathrm{C}$. The following day, the virus was removed and cells were grown in the usual media plus $400 \mu \mathrm{g} / \mathrm{ml}$ neomycin. Cells were maintained in selective media. Retrovirus was generated as previously described (Andrews et al., 2009).

\section{PC12 cell differentiation}

PC12 cells were primed at low density in the usual culture media supplemented with $50 \mathrm{ng} / \mathrm{ml} \mathrm{NGF}$ (Sigma-Aldrich) for $10 \mathrm{~d}$, and stored at $-80^{\circ} \mathrm{C}$ or used immediately. Primed PC1 2 cells were differentiated in the usual media supplemented with $50 \mathrm{ng} / \mathrm{ml} \mathrm{NGF}$ (Sigma-Aldrich) and analyzed after $2 \mathrm{~d}$. Cells were therefore analyzed a total of $12 \mathrm{~d}$ after treatment with NGF. Cells expressing $\alpha 9$ integrin were routinely grown on collagen, as we have previously shown that PC12 cells produce the $\alpha 9 \beta 1$ integrin ligand tenascin-C (Andrews et al., 2009).

\section{Analysis of PC12 cell neurite length}

Neurite outgrowth analysis of primed PC12 cells was performed $2 \mathrm{~d}$ after plating in differentiation media (a total of $12 \mathrm{~d}$ in the presence of NGF). Cultures were fixed with $3 \%$ paraformaldehyde (PFA), and either labeled for $\beta$ neuronal tubulin (TUJ1) or Alexa-conjugated anti- $\beta 1$ integrin, and analyzed for quantification of neurite length. Neurite outgrowth was analyzed by fluorescent microscopy using a Leica DM6000 microscope and Leica LAS AF software to measure the length of neurites in micrometers. The longest neurites of 50 cells were measured per coverslip. Three coverslips were analyzed per experiment, and three experiments were performed. GraphPad Prism, version 3.02, was used for statistical analysis of data.

\section{Percentage of cells with neurites}

Cells were differentiated, fixed, and labeled as described above, and viewed with a Leica DM6000 microscope. Cells with processes longer than two cell body widths were counted as bearing neurites. Three coverslips were analyzed per experiment, and three experiments were performed. GraphPad Prism, version 3.02, was used for statistical analysis of data.

\section{Determination of Rab11/RCP effects on $\alpha 9$ integrin-dependent} growth cone morphology and neurite outgrowth

For growth cone analysis, PC12 cells stably expressing $\alpha 9$ integrin were differentiated as described above. For neurite outgrowth analysis, wildtype PC12 cells and PC12 cells stably expressing $\alpha 9$ integrin were used. After $10 \mathrm{~d}$ in the presence of NGF, cells were trypsinized and electroporated with either Rab11 or RCP DNA constructs or short interfering RNA (siRNA) using the DigitalBio Mircroporator. Control cells were mock transfected for neurite outgrowth or transfected with GFP to enable growth cone analysis. Cells were then plated onto 24-well culture plates coated with $5 \mu \mathrm{g} / \mathrm{ml}$ tenascin (Millipore) and grown for $2 \mathrm{~d}$ in the usual differentiation media but without antibiotics. All cells were additionally cultured in the presence of the $\alpha 9 \beta 1$ blocking antibody Y9A2 (Abcam) at $1: 300$, a concentration we previously determined as generating a partial block of function. Cells were then fixed and visualized in situ either by phase contrast microscopy or by virtue of GFP signal or Cy3 tag (for siRNA). Growth cone size was measured using Leica LAS AF software. Twenty growth cones were analyzed per condition, and three experiments were performed. The longest neurite of 50 cells was measured per condition using Leica LAS AF software, and three experiments were performed. Images were acquired using a Leica AF7000 microscope with a Hamamatsu EM CCD C9100 camera, using $40 \times$ air objective for growth cone analysis.

\section{Adult rat DRG cultures}

Explants. Adult male Sprague Dawley rats were killed, and DRGs were removed and plated onto $1 \mu \mathrm{g} / \mathrm{ml}$ laminin, on poly-D-lysine-coated, acid-washed coverslips. Explants were grown for $72 \mathrm{~h}$ at $37^{\circ} \mathrm{C}$ in DMEM 
supplemented with 10\% FCS (Invitrogen), 1\% penicillin/streptomycin, and $30 \mathrm{ng} / \mathrm{ml} \mathrm{NGF}$.

Dissociated DRGs. Adult male Sprague Dawley rats were killed, and DRGs were removed. DRGs were incubated with $0.1 \%$ collagenase in DMEM for $90 \mathrm{~min}$ at $37^{\circ} \mathrm{C}$, followed by $10 \mathrm{~min}$ in trypsin at $37^{\circ} \mathrm{C}$. DRGs were dissociated by trituration in a blunted glass pipette. Dissociated cells were then centrifuged through a layer of 15\% BSA, washed in DMEM, and cultured on $1 \mu \mathrm{g} / \mathrm{ml}$ laminin, on poly-D-lysine-coated, acid-washed coverslips, in the same media as for DRG explants.

\section{Antibody uptake experiments}

Antibody uptake experiments were performed on primed and differentiated PC12 cells $48 \mathrm{~h}$ after differentiation and on adult DRG explant cultures $72 \mathrm{~h}$ after plating. Cultures were labeled on ice for $30 \mathrm{~min}$ with the Alexa 488-conjugated $\beta 1$ integrin antibody described above, at a concentration of 1:100 diluted in L15 media (Invitrogen) supplemented with 3\% BSA. Cultures were then washed three times with PBS to remove unbound antibody and returned to $37^{\circ} \mathrm{C}$ in the usual culture media for 15 min to allow for internalization. Surface-bound antibody was then removed with an acid wash $(0.5 \mathrm{M} \mathrm{NaCl}$ and $0.2 \mathrm{M}$ acetic acid) for $4 \mathrm{~min}$, followed by washing three times with PBS. Cultures were then returned to $37^{\circ} \mathrm{C}$ and fixed with $3 \%$ PFA after various time points. Cells were then colabeled for Rab11, and images of growth cones were acquired by confocal microscopy.

Colocalization of internalized integrins with Rab11 was quantified using NIH ImageJ software and JACoP (Bolte and Cordelières, 2006) to analyze the colocalization correlation coefficient.

\section{Antibody uptake using compartmented DRG cultures}

Separation of DRG axon and cell body compartments was achieved using Campenot chambers (Tyler Research). Cultures were set up following an established protocol (Pazyra-Murphy and Segal, 2008), modified to increase growth into the axonal compartment, and using permanox chamber slides (Nalge Nunc International). Further to the reported method, $10 \mu \mathrm{g} / \mathrm{ml}$ laminin was added to the methyl cellulose bridge. After $24 \mathrm{~h}$ at $37^{\circ} \mathrm{C}$ to test for leakage, watertight chambers were coated with $1 \mu \mathrm{g} / \mathrm{ml}$ laminin in the somatic compartment, and $10 \mu \mathrm{g} / \mathrm{ml} \mathrm{laminin}$ in the axonal compartment for $3 \mathrm{~h}$ at $37^{\circ} \mathrm{C}$. Dissociated cells were then plated in the usual DRG culture media (see above) but with $10 \mathrm{ng} / \mathrm{ml} \mathrm{NGF}$ in the somatic compartment and $100 \mathrm{ng} / \mathrm{ml}$ in the axonal compartment. Antibody uptake experiments were performed after $6 \mathrm{~d}$ in culture. The somatic compartment was labeled live with the $\beta 1$ integrin antibody described above conjugated to Alexa 488 at a concentration of 1:100, at $37^{\circ} \mathrm{C}$ for $2 \mathrm{~h}$. Cells were then fixed with $3 \%$ PFA with the dividers in place and subsequently labeled with the same antibody on the somatic compartment, but conjugated to Alexa 647. The dividers were then removed for coverslipping. Fluorescent microscopy was performed using a Leica DM6000B microscope. Images of the axonal and somatic compartments were acquired using identical settings as stored using Leica LAS AF software. A minimum of five chambers were used per experiment, and experiments were performed in triplicate.

\section{Transfection of dissociated adult DRG neurons}

DRG neurons were removed and dissociated as described above. Cells were transfected with plasmid DNA encoding GFP-tagged constructs or GFP alone as a control. Transfection was achieved using a Microporator (Digital Bio), which electroporates within a micropipette tip and avoids the adverse effects associated with standard electroporation devices. Approximately $1 \times 10^{5}$ cells were transfected per reaction, in a volume of 10 $\mu$ l. A total of $6 \times 10^{5}$ cells was used per experiment. Transfected cells were plated and culture as described above, but without antibiotics.

\section{Analysis of DRG neurite outgrowth from transfected cells}

Cells were dissociated, transfected, and plated as described above, and fixed after $48 \mathrm{~h}$ in culture. Transfected cells were identified by their GFP signal, viewed with a Leica DM6000 microscope, and Leica LAS AF software was used to trace and measure the length of neurites in micrometers. The longest neurites of all transfected cells were measured for each experiment. Between 25 and 110 neurons were analyzed per condition per experiment. On average, 73 neurons were analyzed per condition. GraphPad Prism, version 3.02, was used for statistical analysis of data.

\section{Analysis of growth cone morphology}

Growth cones of adult DRG neurons were analyzed for their size, and for the number and length of filopodia. DRGs were cultured and fixed as described above. Cells were labeled for $\beta 1$ integrin, and images were acquired using a Leica TCS SPE confocal microscope and Leica LAS AF software. Stacks of images were acquired through the entire depth of the growth cone, and maximum projection images were analyzed. The area of growth cones was delineated and quantified using Leica LAS AF software, as adjudged by immunofluorescence of $\beta 1$ integrin, which labels the growth cone in its entirety (see supplemental Fig. S1, available at www.jneurosci.org as supplemental material); filopodia $>3 \mu \mathrm{m}$ were counted. Filopodia were traced and measured in micrometers using Leica LAS AF software. The largest growth cones of 20 randomly chosen neurons were analyzed per experiment, and experiments were performed in triplicate.

\section{Quantification of growth cone $\beta 1$ integrin immunofluorescence}

$\beta 1$ integrins were detected by immunofluorescence using the directly conjugated $\beta 1$ integrin antibody described above, at a concentration of $1: 100$. Images of growth cones were acquired by confocal laser-scanning microscopy using a $63 \times$ objective and a Leica TCS SPE confocal microscope. Initial observations were made on three test growth cones per condition, and detection settings were adjusted so that the pixel intensities of acquired images were below saturation. Settings were then stored and were applied for the identical acquisition of each image using Leica LAS AF software. Four confocal sections were acquired for each image, spanning the entire depth of each growth cone. Maximum projection images were then created and used for analysis. Lines were then traced around the periphery of each growth cone to define the region of interest, and total pixel intensities per growth cone were quantified using Leica LAS AF software. The acquired images were corrected for background by subtracting an identical region of interest adjacent to the growth cone being analyzed. Twenty growth cones were analyzed per experiment, and all experiments were performed in triplicate. Quantification of peripheral versus central fluorescence was quantified essentially in the same manner. First, a region of interest was defined around the periphery of the growth cone, and a second region was defined in the central domain. The ratio of peripheral versus central enrichment was calculated as the mean fluorescence intensity at the growth cone periphery divided by the mean fluorescence intensity in the central domain. A ratio of 1 represents a uniform distribution, whereas a ratio $>1$ represents peripheral enrichment.

\section{Quantification of $\beta 1$ integrin cell surface expression by membrane biotinylation}

Quantification of cell surface integrins was performed following an adaptation of an established protocol (Milner and ffrench-Constant, 1994), using the Pierce cell surface protein isolation kit (Pierce Biotechnology). Briefly, cells were labeled with sulfo-NHS-SS-biotin for $30 \mathrm{~min}$, and then lysed and sonicated in lysis buffer. Biotinylated proteins were isolated using NeutrAvidin gel on a column. Protein levels in the lysate were determined using the BCA protein assay (Pierce), and volumes were adjusted to normalize protein density. An aliquot of the normalized lysate was used for Western blot assessment of total integrin protein levels. Biotinylated proteins were then recovered in sample buffer with DTT and subsequently loaded onto NuPage BisTris gels (Invitrogen) for Western blot analysis. $\beta 1$ integrin was detected using the antibody AB1952 (Millipore), and $\beta$-actin was detected using the antibody AC-15 (Abcam). Immunoreactivity was detected using ECL Plus (GE Healthcare), and densitometry was performed with NIH ImageJ software.

\section{Subcellular fractionation followed by immunoisolation of Rab11 endosomes}

PC12 cells were differentiated for $12 \mathrm{~d}$ at low density in $75 \mathrm{~cm}^{2}$ dishes and used for detergent-free subcellular fractionation. Cells were homogenized through a 21 gauge needle in detergent-free homogenization buffer 
(250 mm sucrose, 3 mм imidazole, 1 mm EDTA, and protease inhibitors, pH 7.4), and a postnuclear supernatant (PNS) was generated by standard techniques (Bomsel et al., 1990). The PNS was adjusted to $40.6 \%$ sucrose in $3 \mathrm{~mm}$ imidazole, $1 \mathrm{~mm}$ EDTA, $\mathrm{pH}$ 7.4. This was then loaded on the bottom of an ultraclear SW55 TI centrifuge tube (Beckman Coulter) and overlaid sequentially with $1.5 \mathrm{ml}$ of $35 \%$ sucrose, $1 \mathrm{ml}$ of $25 \%$ sucrose, and filled to the top with $1.5 \mathrm{ml}$ of homogenization buffer. This was centrifuged at $130,000 \times g$ for $1.5 \mathrm{~h}$ at $4^{\circ} \mathrm{C}$ using an SW55 TI rotor (Beckman Coulter). After centrifugation, gradients were collected from top (fraction 1) to bottom (fraction 8). The interface between the 25 and $35 \%$ was isolated as fraction 5 . Protein concentration at each fraction was determined using BCA protein assay (Pierce). Equal volumes from each fraction were analyzed by Western blotting, and loading was analyzed by Ponceau staining the membranes (supplemental Fig. S2 A, available at www.jneurosci.org as supplemental material). Fractionation was analyzed using subcellular markers (supplemental Fig. S2 B, available at www.jneurosci.org as supplemental material), and fraction 5 was used as starting material for immunoisolation using magnetic protein $\mathrm{G}$ microbeads (Miltenyi Biotec) coated with Rab11 antibody (Invitrogen) under detergent-free conditions. Starting material was first precleared using unlabeled protein $\mathrm{G}$ beads, and the elute was used as a negative control (PC). Precleared material from fraction 5 was also incubated with rabbit $\mathrm{IgG}$ as an additional control. Equal proportions of starting material (SM), nonbound material (NB), and bound material (B) and precleared or control material were analyzed by Western blotting.

\section{Microscopy}

Three microscopes were used in this study, as has been indicated. Laserscanning confocal microscopy was performed using a Leica DMI4000B microscope, with laser scanning and detection achieved by a Leica TCS SPE confocal system controlled with Leica LAS AF software. Standard fluorescent microscopy was performed using a Leica DM6000B with a Leica DFC350 FX CCD camera and a Leica AF7000 with a Hamamatsu EM CCD C9100 camera and Leica LAS AF software. Live-cell imaging was performed with an Olympus IX70 microscope using a Hamamatsu ORCA-ER CCD camera and a PerkinElmer UltraVIEW scanner for spinning disk confocal microscopy, controlled with MetaMorph software. Kymographs were generated using MetaMorph software. Instantaneous velocity was calculated using MetaMorph software to measure the distance moved by a vesicle between two consecutive frames. Vesicles were tracked for their visible lifetime, and the maximum distance moved between two frames was measured and used to calculate instantaneous speed. The distance covered by vesicles over time was measured as the maximum net distance a vesicle moved over 10 frames (30 s). Fifty vesicles were analyzed per condition per experiment, over three experiments. Velocities were binned into $0.2 \mu \mathrm{m} / \mathrm{s}$, and distance was binned into 0.5 $\mu \mathrm{m}$. Images for presentation were processed in their entirety with Leica and Photoshop (Adobe) software. Images acquired for quantification were analyzed raw.

\section{RNA interference of Rab11}

Suppression of Rab11 expression was performed by RNA interference using two specific siRNA oligonucleotides purchased from Ambion (Applied Biosystems) targeted to rat Rab1la and Rab11b mRNA sequences. The Rab1la siRNA sequence corresponds to 5'-GGGCAGUUCCUACAGAUGA-3'. Oligonucleotides directed to Rab11b were fluorescently tagged with a Cy3 label on the antisense strand and correspond to 5'-GAAACGAGUUCAACCUAGA-3', of the rat mRNA sequence. For control experiments, Ambion silencer Cy3-labeled negative control 1 (Applied Biosystems) was used. Oligonucleotides targeting Rab1la and Rab11b were cotransfected at equimolar concentrations into primed PC12 cells using the Digital Bio Microporator (described above). Transfected PC12 cells were differentiated as described above and analyzed after $48 \mathrm{~h}$.

Assessment of Rab11 protein suppression after siRNA treatment Rab11 protein suppression was assessed $48 \mathrm{~h}$ after transfection with siRNA. Cells were lysed in RIPA buffer and protein concentration of lysate was determined using the BCA protein assay (Pierce). Equal amounts of lysate were analyzed by Western blot. Blots were probed for
Rab11, then stripped and reprobed for actin, and then stripped and reprobed for ARF6. A $25 \mathrm{~cm}^{2}$ flask of subconfluent PC12 cells was used for each condition (mock transfected, control siRNA transfected, and Rab11 siRNA transfected). Three experiments were performed. Reduction of Rab11 expression was quantified by densitometry.

\section{Quantification of Rab11 immunofluorescence after siRNA treatment}

Rab11 protein suppression was identified by immunofluorescence analysis using the Rab11 antibody described above at a concentration of 1:50 and compared with control cells transfected with Cy3-tagged control siRNA. Primary antibody was detected using secondary Alexa-647 goat anti-rabbit (Invitrogen) at a concentration of 1:800. Rab11 suppression at the growth cone was quantified by analysis of images acquired by confocal microscopy as described above for quantification of $\beta 1$ integrin immunofluorescence. Somatic Rab11 immunofluorescence was quantified using a Leica DM6000 microscope and Leica LAS AF software. Initial observations were made and exposure times were adjusted so that the pixel intensities were below saturation. Settings were then stored and were applied for the identical acquisition of each image using Leica LAS AF software. Immunofluorescence was quantified on 20 soma per condition and all experiments were performed in triplicate.

\section{siRNA target validation}

The Rab1la siRNA sequence (5' -gggcaguuccuacagauga- $\left.3^{\prime}\right)$ targets base pairs 394-413 (agggcagttcctacagatga) of the Rab11 CDS. Primers were designed to introduce three silent mutations into this region $\left(5^{\prime}\right.$ gtgatttacgtcatctcagggctgtaccaacagatgaagcaagagcatttgcag- $3^{\prime}$ ) (bold shows target sequence of the siRNA), and an siRNA-resistant Rab11GFP construct was created by site-directed mutagenesis using the Rab11GFP construct described above as a template. Mutagenesis was confirmed by DNA sequencing. PC12 cells stably expressing siRNAresistant Rab11 were then generated as described in Materials and Methods. Stable Rab11-GFP PC12 cells and siRNA-resistant cells were then primed and transfected with siRNA targeting Rab11 and differentiated for $2 \mathrm{~d}$ in the presence of NGF. RAB11-GFP PC12 cells were also transfected with control siRNA. Cells were then assayed for GFP fluorescence, growth cone $\beta 1$ integrin fluorescence, and neurite length. Twenty growth cones were analyzed per experiment, and the longest neurite of 50 randomly chosen cells was measured per experiment. Two experiments were performed.

\section{Results}

Our experiments address the mechanism of integrin trafficking in axons. We ask whether integrins traffic in Rab11 vesicles, whether the Rab11 effector RCP regulates trafficking, and whether manipulation of the pathway affects axon growth. We have focused particularly on $\alpha 9 \beta 1$ integrin because of its ability to promote axon regeneration in the CNS, and because axon growth from $\alpha 9$-transfected neurons on tenascin provides an assay in which one can be certain that growth is integrin mediated. We performed initial assays on differentiated PC12 cells because stably transfected cells generally express transgenes at near-normal levels and because it is possible to obtain sufficient material for biochemical assays. We then validated the PC12 findings in adult DRG axons, finding essentially identical results. We present data to demonstrate that $\alpha 9$ and $\beta 1$ integrins traffic to the growth cone via Rab11 (Figs. 1-5) and that the Rab11 effector RCP regulates integrin trafficking to the growth cone surface (Figs. 6-8). Finally, we examine the effects of manipulating the Rab11/RCP pathway on neurite outgrowth (Figs. 9-11).

\section{Do integrins colocalize with Rab11 at the growth cone?}

If Rab11 is involved in trafficking integrins to the growth cone, the two molecules ought to colocalize there. $\alpha 9$ is not expressed by PC12 cells or adult DRG neurons, so we created an $\alpha 9$ integrin construct in which GFP was fused to the C-terminal through an 
amino acid linker to minimize steric effects. We generated four PC12 lines stably expressing this construct so as to avoid artifacts associated with transient overexpression. We first checked that the construct was functional by comparing the effects on PC12 cells of either stable $\alpha 9$-GFP expression or stable untagged $\alpha 9$ integrin expression (supplemental Fig. S1, available at www.jneurosci.org as supplemental material). The PC12 cells were differentiated for $12 \mathrm{~d}$ to produce mature neurites tipped by growth cones. We found partial overlap between Rab11 staining and $\alpha 9$-GFP fluorescence in overlapping vesicular structures at the growth cone (Fig. 1A, top panels, inset and arrows), but most obviously throughout the filopodia (seen above the dotted lines in Fig. $1 A$, top panels). We also investigated the distribution of endogenous $\beta 1$ integrins in PC12 cells (using a directly conjugated anti- $\beta 1-488$ antibody) and again found partial overlap with Rab11 in filopodia and in vesicular structures (Fig. $1 A$, bottom panels). This suggests that integrins and Rab11 may colocalize to the same structures. Rab11 was also found to overlap with $\alpha$ and $\beta 1$ integrins in adult DRG neurons. Transfected $\alpha 9$-GFP overlapped with Rab11 as in PC12 cells (data not shown), and we also examined the localization of two endogenous integrins and found partial overlap of both $\beta 1$ and $\alpha 3$ with Rab11 at the growth cone periphery and in individual vesicular structures (Fig. $1 B$ ). These data suggest that multiple integrins may colocalize with Rab11 vesicles at the growth cones of peripheral neurons. To confirm that integrins are present in Rab11 structures, we performed subcellular fractionation followed by immunoisolation of Rab11-positive organelles from $\alpha 9$-GFP transfected PC12 cells. We used detergent-free lysis followed by flotation in a sucrose step gradient designed to enrich for endosomes (Gorvel et al., 1991) and analyzed the resulting fractions by Western blot. We found that both Rab11 and integrins were enriched in fraction 5 (Fig. 1C). This fraction also labeled strongly for the early endosome marker Rab5, whereas markers for the endoplasmic reticulum and Golgi labeled heavier membranes in fractions 8 and 7 (supplemental Fig. S2B, available at www. jneurosci.org as supplemental material). We then used material from fraction 5 for immunoisolation using magnetic microbeads coated with antibodies to Rab11. Equal volumes of starting material (SM), nonbound (NB), and bound (B) material were analyzed by Western blotting, in conjunction with preclear elute (PC) as control. We found both $\alpha 9$ and $\beta 1$

C
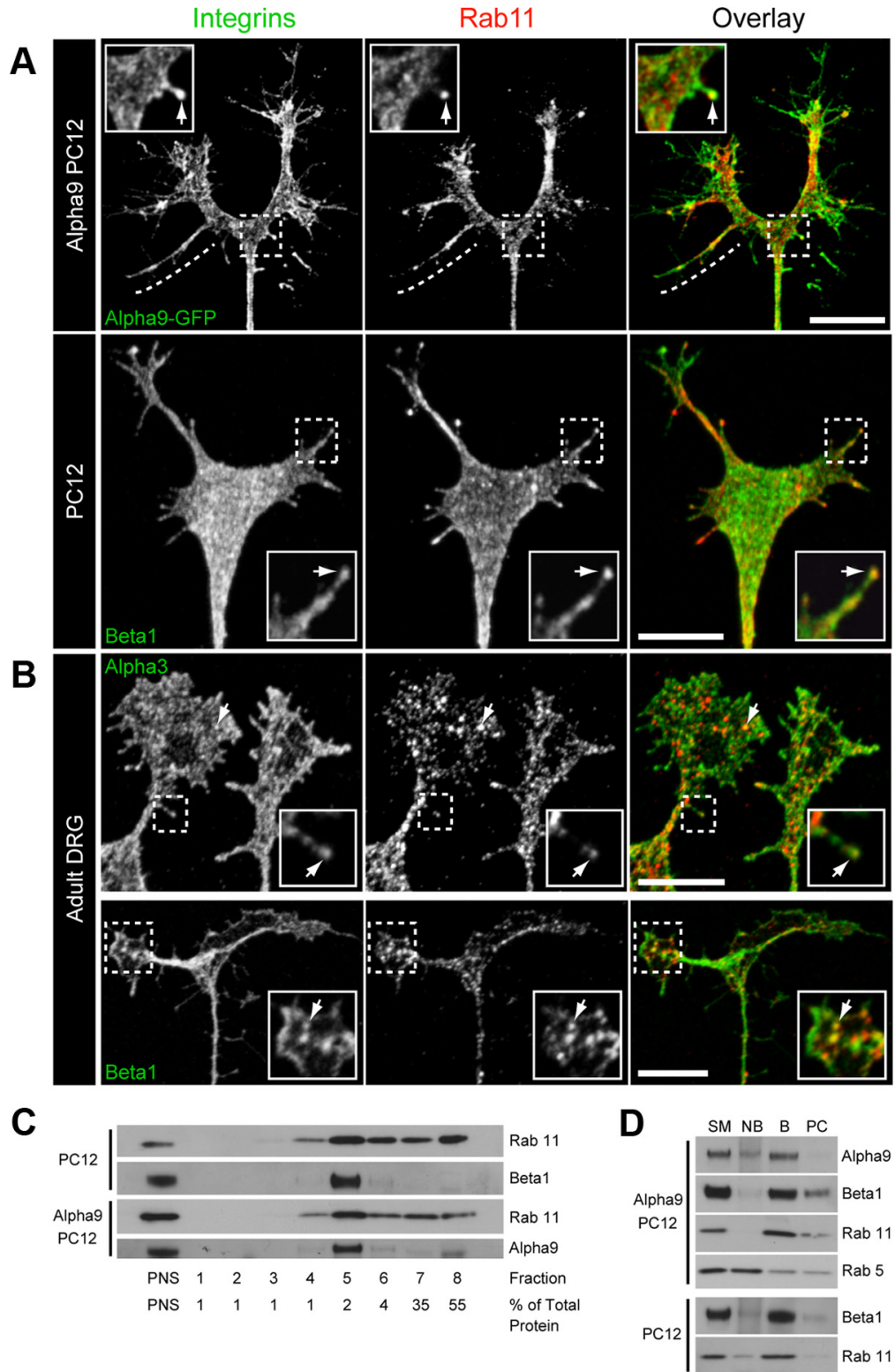

Figure 1. Integrins partially colocalize with Rab11 at the growth cone. Images show growth cones of differentiated PC12 cells (A) and adult DRG neurons (B). PC12 cells stably transfected with $\alpha 9$ integrin-GFP exhibit partial overlap of $\alpha 9$-GFP and antibodylabeled Rab11 ( $\boldsymbol{A}$, top panels). The dotted line in $\boldsymbol{A}$ indicates overlap of fluorescent signal within filopodia. The $\alpha 9$ partner $\beta 1$ integrin was detected using anti- $\beta 1-488$ and partly overlaps with Rab11 at $\mathrm{PC} 12$ growth cones in vesicular structures in $A$ (bottom panels arrows). Endogenous $\alpha 3$ and $\beta 1$ integrins also partly overlap with Rab11 at adult DRG growth cones (B). PC12 cells were treated with NGF for a total of $12 \mathrm{~d}$ before fixation. Dissociated adult DRGs were fixed after $2 \mathrm{~d}$ in vitro. Main images are maximumintensity projections of confocal images. The inset panels show coincident labeling in a single confocal section, and the arrows indicate overlap in vesicular structures. Scale bars, $10 \mu \mathrm{m}$. Rab11 endosomes in differentiated PC12 cells and $\alpha 9-\mathrm{PC} 12$ cells were also analyzed by subcellular fractionation $(\boldsymbol{C}, \boldsymbol{D})$. A PNS was generated after detergent-free lysis, and sucrose gradient fractionation was then performed. Fractions were analyzed by Western blotting (gels were loaded with equal volumes of fractions 1-8) (C). Rab11 endosomes were enriched at the interface between the 25 and $35 \%$ sucrose fractions (fraction 5, C). $\alpha 9$ and $\beta 1$ integrins were also enriched in this fraction. This fraction was used as starting material (SM) for immunoisolation using magnetic microbeads. Equal proportions of starting material, nonbound (NB), and bound (B) material were analyzed by Western blotting, in conjunction with preclear elute (PC) as control (D). $\alpha 9$ and $\beta 1$ integrins were enriched in the bound fraction, indicating their presence in Rab11 structures. This fraction also labeled strongly for Rab11, but weakly for the early endosomal marker Rab5, which was enriched in the nonbound flow-through.

integrins enriched in the bound fraction (Fig. 1D), indicating that Rab11 endosomes contain these integrins. We confirmed the specificity of the Rab11 isolation by probing Western blots for Rab11 and Rab5, and also by incubating starting material with beads coated with IgG as an additional negative control. We 


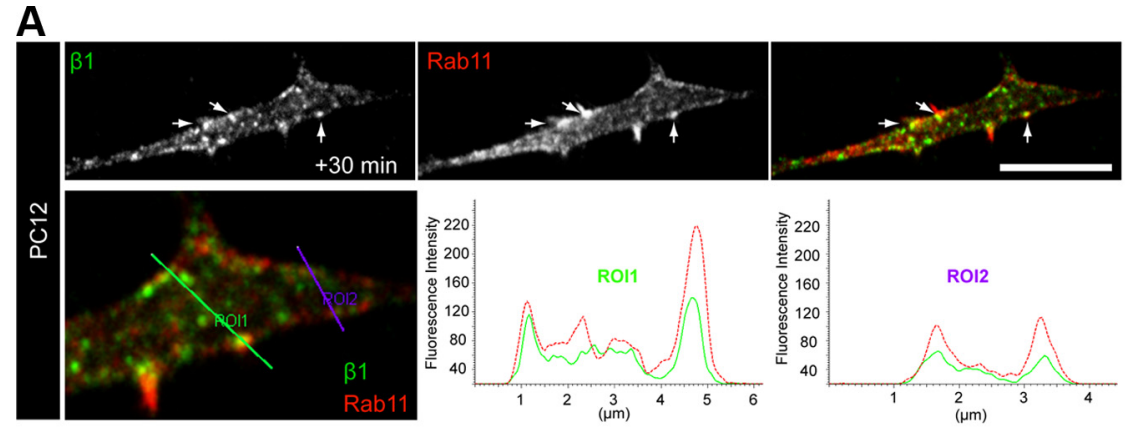

B
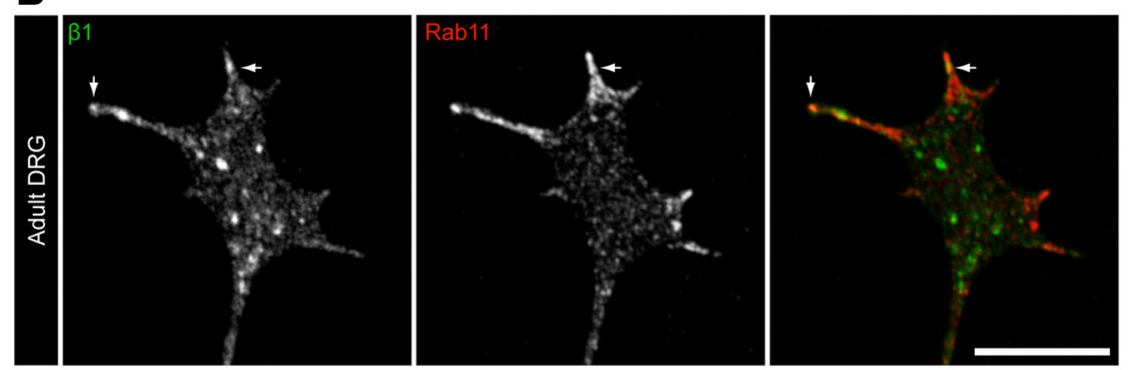

C
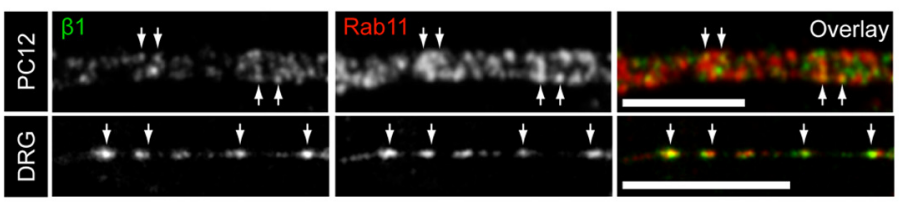

D

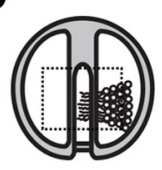

1. $\beta 1-488$ added live to somatic chamber only for $2 \mathrm{hr}$ at $37^{\circ} \mathrm{C}$

2. PFA added to both chambers.

3. $\beta 1-647$ added to somatic chamber.

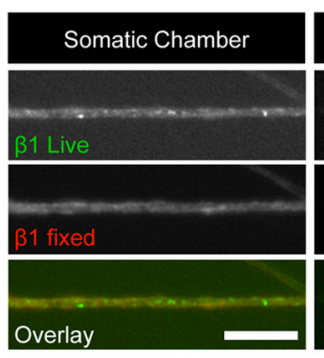

Overlay

Figure 2. Internalized $\beta 1$ integrins traffic through Rab11-positive endosomes and travel anterogradely. Antibody uptake experiments were performed on PC12 $(\boldsymbol{A})$ and adult DRG growth cones $(\boldsymbol{B})$ using anti- $\beta 1$-488 and colabeled for Rab11. The images show only internalized integrins, after removal of surface antibody. Analysis of fluorescence intensity across the growth cone is shown in $\boldsymbol{A}$, bottom panels. Internalized $\beta 1$ integrins partly overlap with Rab11 in axons and neurites (C). Adult DRGs were grown in compartmented cultures $(\boldsymbol{D})$, and $\beta 1$ integrins were labeled live with anti- $\beta 1-488$ in the somatic compartment. $\beta 1$ integrins were subsequently observed in the axonal compartment after $2 \mathrm{~h}$ at $37^{\circ} \mathrm{C}(\boldsymbol{D}$, right-hand panel). All images are single confocal sections, except for $\boldsymbol{D}$, which was acquired using standard fluorescent microscopy. The images in $\boldsymbol{D}$ were acquired using identical exposure settings for the axon and somatic compartment. The arrows indicate overlap of fluorescent signal. Scale bars, $10 \mu \mathrm{m}$. The images are representative of the results from experiments performed more than three times.

found that only small amounts of protein were isolated using IgG (supplemental Fig. S2C, available at www.jneurosci.org as supplemental material). Rab11 was enriched in the material isolated using Rab11 antibodies, whereas Rab5 was principally found in the nonbound flow-through (Fig. $1 D$ ). These data confirm that $\alpha 9$ and $\beta 1$ integrins are present in Rab11-positive vesicles in differentiated PC12 cells. Together, these results suggest that integrins may traffic via Rab11-positive vesicles at or en route to the growth cone.

\section{Do endocytosed integrins traffic through Rab11?}

Integrins are continuously internalized and recycled to the cell surface. We asked whether internalized $\beta 1$ passes through Rab11 vesicles in PC12 cells and DRG axons. To do this, we bound $\beta 1-488$ antibody to the cell surface of differentiated cells placed
Axonal Chamber

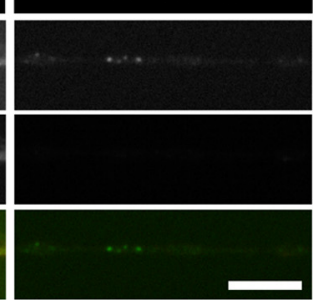

on ice to halt endocytosis, and then restarted trafficking by warming the cells to $37^{\circ} \mathrm{C}$. After $30 \mathrm{~min}$ at $37^{\circ} \mathrm{C}$, internalized $\beta 1$ integrins localized along with perinuclear Rab11 (supplemental Fig. S3A, available at www. jneurosci.org as supplemental material) in keeping with findings in non-neuronal cells (Powelka et al., 2004). There was also overlap between internalized $\beta 1$ integrins and Rab11 in the growth cones of both PC12 cells and DRG axons (Fig. $2 A, B)$. Coincident fluorescence was found at all time points from 15 min up to 90 min after starting internalization, and by $30 \mathrm{~min}$ labeled integrin was found at the growth cone periphery localized to Rab11-positive structures (Fig. 2A). Analysis of the fluorescence intensity profile across a PC12 growth cone demonstrated coincident peaks for internalized $\beta 1$ integrins and Rab11 (Fig. 2A), and overlap at the growth cone periphery even at regions of low signal (Fig. 2A, ROI2). Quantification of coincident fluorescence revealed that there was little variation in the colocalization correlation coefficient between $\beta 1$ integrins and Rab11 over time (supplemental Fig. S3B, available at www. jneurosci.org as supplemental material), and we found no time lag between internalization and arrival at a Rab11 domain. This suggests that integrins do not have to be transported for long distances, and certainly not to the cell body to enter the Rab11 compartment, and hints at localized Rab11-dependent trafficking. Examination of internalization in adult DRG neurons labeled live at $4^{\circ} \mathrm{C}$ with $\beta 1-488$ was complicated by partial retraction of their axons. However, we were able to study trafficking as the axons reestablished their growth cones and continued to grow within $60 \mathrm{~min}$ after returning to $37^{\circ} \mathrm{C}$ (surface-bound antibody was removed after $30 \mathrm{~min}$ ). As with PC12 cells, these growth cones contained internalized $\beta 1$ integrins localized to Rab11-positive structures, most strikingly at the growth cone periphery and in filopodia (Fig. $2 B$ ). These data further suggest that $\beta 1$ integrins may recycle via Rab11 endosomes at the growth cones of PC12 cells and adult DRGs. However, not all internalized integrins were found in a Rab11 compartment (Fig. $2 B)$, suggesting that integrins do not traffic solely via Rab11 membrane compartments and that there may be additional trafficking molecules involved.

\section{Are internalized integrins transported anterogradely along axons?}

We then asked whether internalized integrins are also trafficked down axons toward the growth cone. Using the same antibody internalization strategy, we found that internalized $\beta 1$ integrins overlapped with Rab11 in the neurites of PC12 cells and along the axons of adult DRG neurons (Fig. 2C). In DRG neurons, we 

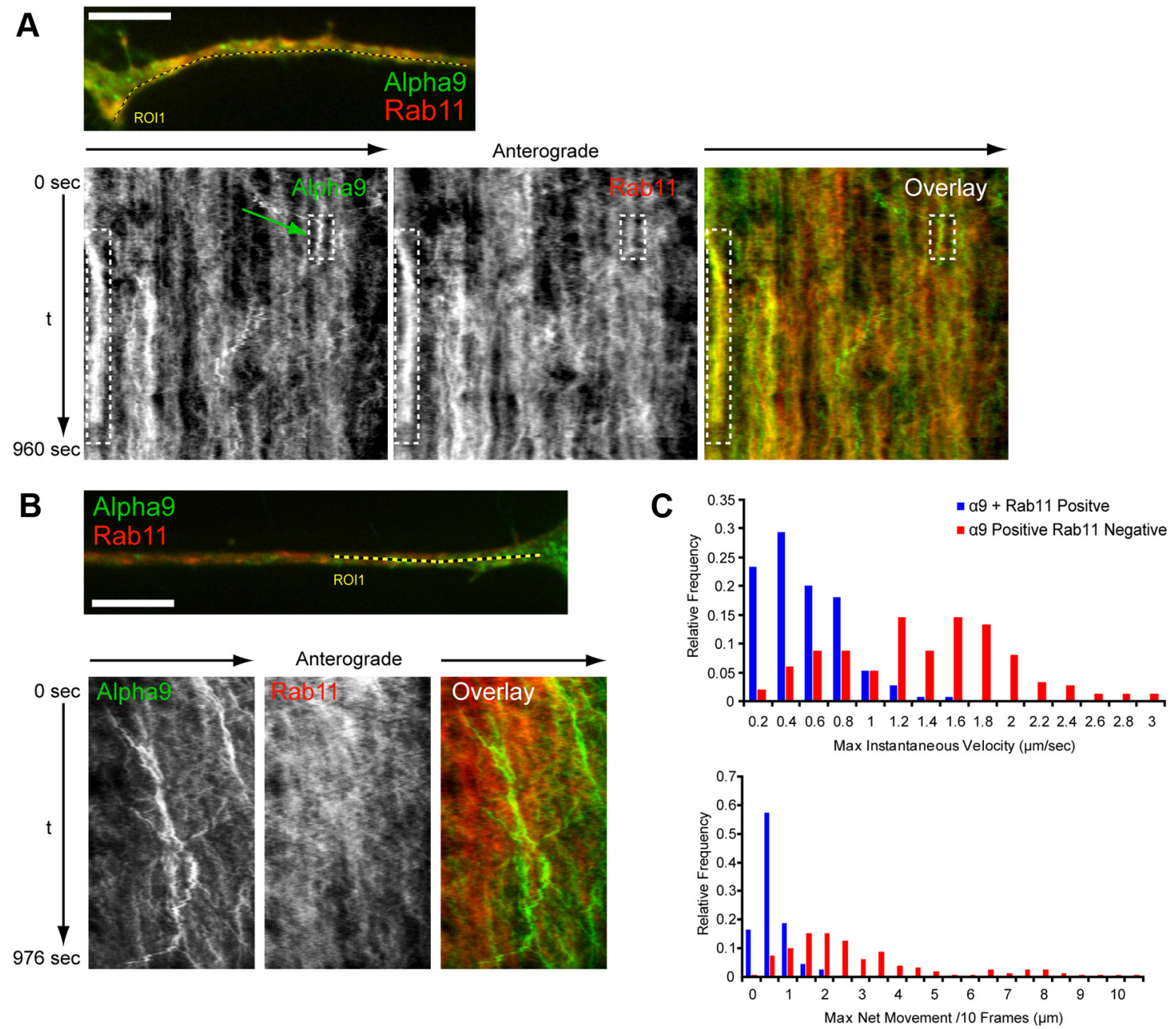

Figure 3. $\alpha 9$ integrin does not appear to undergo long-range anterograde transport in Rab11 vesicles. Spinning disc confocal microscopy was used to image Rab11-cherry in PC12 cells stably expressing $\alpha 9$ integrin-GFP $(\boldsymbol{A}, \boldsymbol{B})$ (see also supplemental Movies S1-S3, available at www.jneurosci.org as supplemental material). The kymograph shown in $\boldsymbol{A}$ was generated from the line indicated. The dotted boxes indicated static coincidence. The green arrow indicates anterogradely moving $\alpha 9$ integrin-GFP. Long-range movement of $\alpha 9$-GFP was generally found to be independent of Rab11 (B). Instantaneous velocity of, and distance moved by, vesicles positive for $\alpha 9 \mathrm{GFP}$ alone (red bars) or dual positive for $\alpha 9 \mathrm{GFP}$ and Rab11-cherry (blue bars) was quantified by tracking individual vesicles ( $(\boldsymbol{C}$. Vesicles were tracked for their visible lifetime and the instantaneous velocity was calculated from the maximum distance moved by a vesicle between two frames (3 s). Maximum net movement over 10 frames is a measure of the furthest a vesicle traveled from its origin over 10 frames. The images are representative of multiple imaging experiments. Scale bar, $5 \mu \mathrm{m}$.

found that $28 \pm 2.4 \%$ (SEM) of internalized $\beta 1$ integrins overlapped with Rab11 within axons at $60 \mathrm{~min}$, and $31 \pm 2.3 \%$ (SEM) at 90 min after starting internalization. Transcytosis (insertion into the somatic surface followed by movement via endocytic vesicles into the axonal surface) contributes to axonal targeting of membrane proteins (Winckler, 2004; Allen and Chilton, 2009). To determine whether transcytosis contributes to axonal trafficking of integrins, we used water-tight Campenot chambers to compartmentalize adult DRG cell bodies from their axons (Fig. $2 D$; supplemental Fig. S3C, $D$, available at www.jneurosci.org as supplemental material) (Pazyra-Murphy and Segal, 2008). The cell body compartment was labeled live with anti- $\beta 1-488$ at $37^{\circ} \mathrm{C}$ for $2 \mathrm{~h}$, after which the cultures were fixed with the dividers in place. The cell body compartment was then labeled with anti- $\beta 1$ 647 to control for passive diffusion of antibody between compartments. $\beta 1-488$ and $\beta 1-647$ were both present in the cell body compartment, where $\beta 1-647$ labeled just the surface of axons, whereas $\beta 1-488$ labeled the surface and intraaxonal puncta (Fig. $2 D$ ). Puncta of $\beta 1-488$ were also visible in $17.6 \%$ of axons in the axonal compartment, where $\beta 1-647$ was absent. This confirms that the dividers were watertight and suggests that internalized $\beta 1-488$ was actively transported along the axons. Together with the previous sections, our data suggest that endocytosed $\beta 1$ integrins traffic via Rab11-positive structures in growth cones and in axons and that, although some of this trafficking may be localized, it also appears to contribute to the anterograde flow of $\beta 1$ integrins.

\section{Are integrins transported anterogradely in}

Rab11-positive vesicles?

To establish whether integrins move anterogradely under the guidance of Rab11, we used live confocal imaging. We first investigated Rab11 dynamics in the neurites of PC12 cells stably expressing Rab11-GFP, using cells with lower levels of expression to avoid overexpression artifacts. Rab11 particles did not undergo long-range movements but rather short-range oscillations, resulting in little net movement over time (supplemental Fig. S4 A, Movie S1, available at www.jneurosci.org as supplemental material). This is similar to the behavior described for the early endosomal marker Rab5 in the axons of motor neurons (Deinhardt et 
$A_{\text {(i) }}$
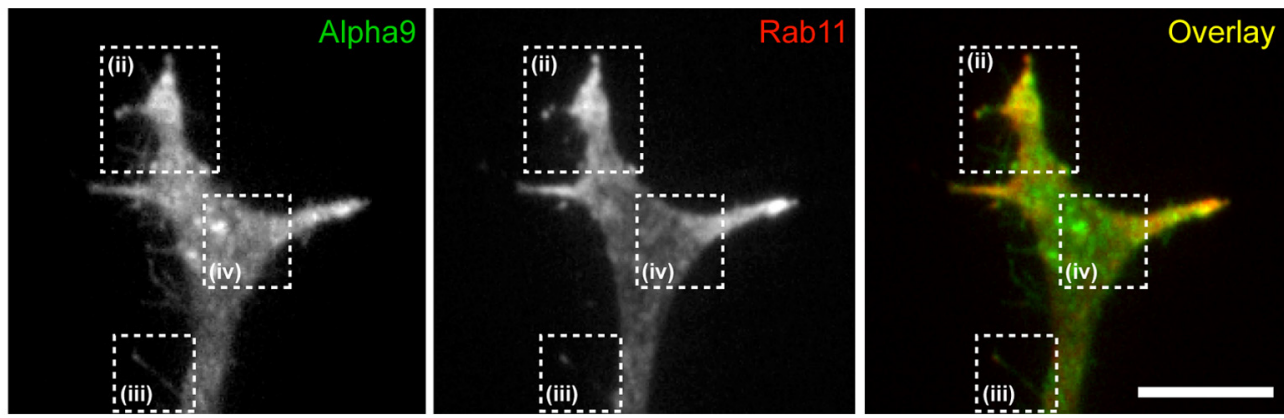

(ii)

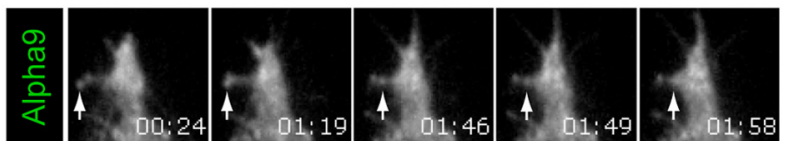

(iii)
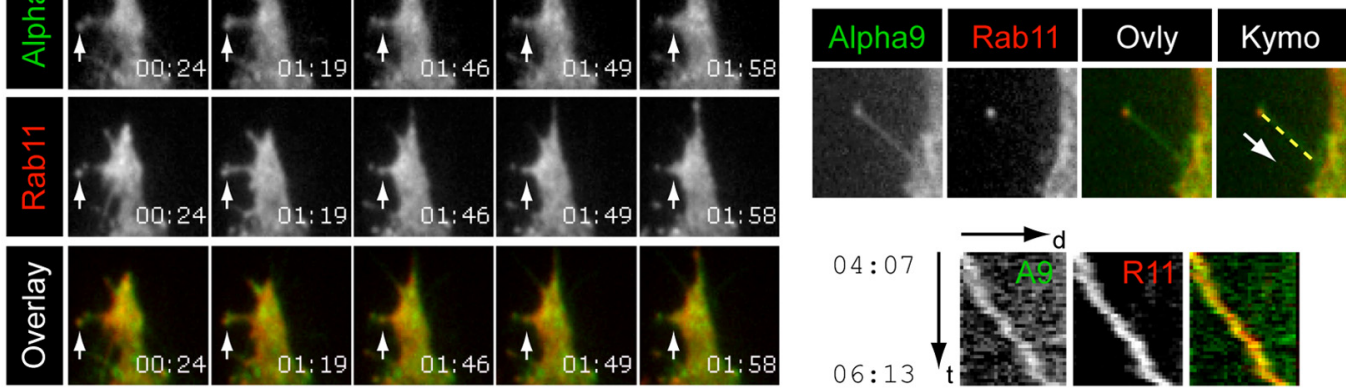

(iv)
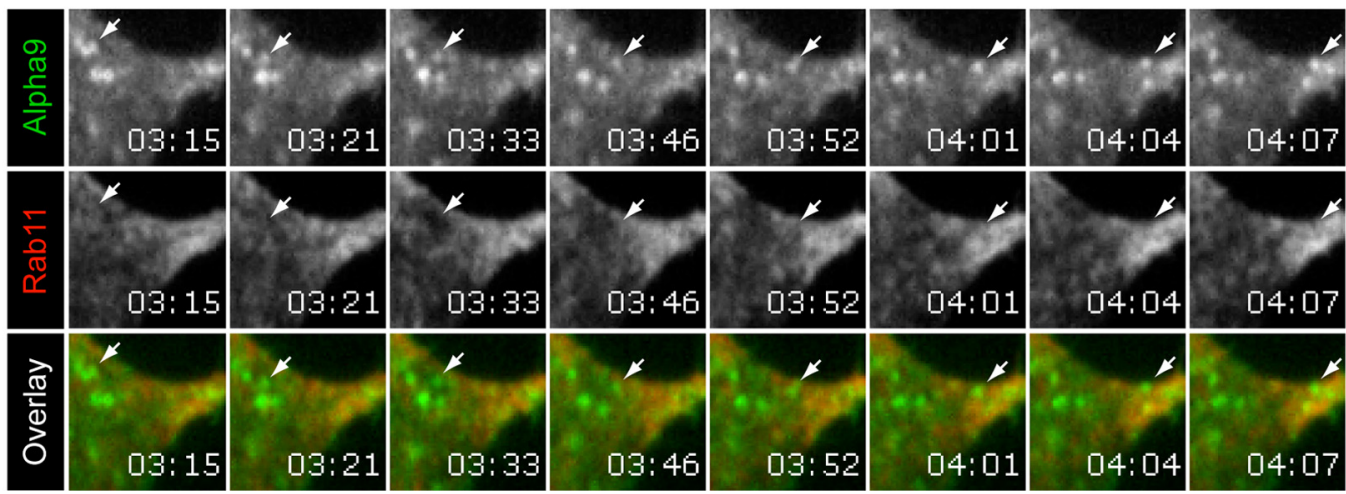

Figure 4. $\alpha 9$ integrin is transported in Rab11 vesicles at the growth cone periphery. Spinning disc confocal microscopy was used to image $\alpha 9$-GFP and Rab11-cherry in differentiated PC12 cell growth cones. A, Growth cone of a PC12 cell stably expressing $\alpha 9$ integrin, coexpressing Rab11-cherry. $\alpha 9$-GFP and Rab11-cherry overlap at points of protrusion (i), and individual puncta can be seen to move in concert in growth cone filopodia (ii, arrows) and along filopodia on neurites, demonstrated by kymography (iii). Large puncta of $\alpha 9$ integrin-GFP in the central domain that are Rab11 negative can be seen to move toward Rab11-positive domains at the growth cone periphery (iv, arrows). The images are representative of multiple imaging experiments. Scale bar, $5 \mu \mathrm{m}$. See also supplemental Movies $\mathrm{S} 4$ and S5 (available at www.jneurosci.org as supplemental material).

al., 2006) and is in partial agreement with findings in sympathetic neurons, where the majority of axonal Rab11 appears stationary (Ascaño et al., 2009). We then investigated the dynamic interactions between Rab11 and $\alpha 9$ integrins using cells stably expressing $\alpha 9$-GFP, and transiently coexpressing Rab11-cherry. $\alpha 9$ GFP and Rab11-cherry overlapped principally at the edge of neurites where they underwent limited movements (Fig. 3A; supplemental Movie S2, available at www.jneurosci.org as supplemental material), as represented by the vertical yellow lines highlighted in the kymograph in Figure $3 A$. However, whereas the integrin in Rab11-positive structures remained relatively static, Rab11-negative $\alpha 9$-GFP puncta intermittently underwent longer range movements in both anterograde and retrograde directions. This is demonstrated in the kymograph in Figure 3B (see supplemental Movie S3, available at www.jneurosci.org as supplemental material), which shows long-range anterograde movement, and by the green arrow in the left-hand panel of the kymographs in Figure $3 A$, indicating a moving punctum of $\alpha 9$-GFP. Importantly, rapidly moving puncta could be seen entering and leaving relatively static Rab11 domains, as in Figure $3 A$ (small dotted box), where an anterogradely moving punctum paused in a Rab11-positive region before reversing direction.

Quantification of instantaneous velocity confirmed that the majority $(\sim 73 \%)$ of double-positive (Rab11-cherry and $\alpha 9$ GFP) vesicles moved very slowly, with a maximum speed of $<0.6$ $\mu \mathrm{m} / \mathrm{s}$ (Fig. $3 C$, top graph, blue bars). Rab11-negative $\alpha 9$-GFPpositive vesicles were present in two populations, the slower $\sim 30 \%$ moved at a rate of $<1 \mu \mathrm{m} / \mathrm{s}$, whereas the larger population moved at a velocity between 1 and $3 \mu \mathrm{m} / \mathrm{s}$ (Fig. 3C, top graph, red bars). We also quantified the maximum net distance a vesicle traveled over a given time (10 frames, $30 \mathrm{~s}$ ). This confirmed that the majority of double-positive vesicles had little net movement over time, with $\sim 90 \%$ of vesicles moving $<1 \mu \mathrm{m}$ in $30 \mathrm{~s}$ (Fig. 3C, bottom graph, blue bars). However, Rab11negative $\alpha 9$-GFP vesicles covered much greater distances (from $0.2 \mu \mathrm{m} / 30 \mathrm{~s}$ to $10.4 \mu \mathrm{m} / 30 \mathrm{~s}$ ) (Fig. 3C, bottom graph, red bars). These data suggest that integrins move in and out of 
Rab11-positive domains, with long-range transport in Rab11-negative vesicles.

Are integrins transported in Rab11positive vesicles at the growth cone? We also investigated Rab11 and $\alpha 9$ integrin dynamics at the growth cone. Using stably transfected Rab11-GFP PC12s (supplemental Fig. S4B, Movie S4, available at www.jneurosci.org as supplemental material), and $\alpha 9$-GFP cells transfected with Rab11-cherry, we saw rapidly moving small puncta throughout the growth cone and particularly in filopodia and protrusive regions, many containing both Rab11 and $\alpha 9$. (Fig. 4Ai; supplemental Movie S5, available at www.jneurosci.org as supplemental material). At the base of protrusive regions, the puncta often joined larger stationary regions (Fig. 4 Aii). This suggests that recycling filopodial $\alpha 9$ integrins move via Rab11 vesicles into a stable Rab11 domain within the growth cone. Similar movement was observed in filopodia on neurites (Fig. 4 Aiii). There were also larger $\alpha 9$-GFP aggregates in the central domain of the growth cone that remained Rab11 negative, similar to the large $\beta 1$ integrin aggregates seen in the center of both PC12 and DRG growth cones after antibody internalization (Fig. $2 A, B$ ). Puncta in these aggregates mostly remained in the central domain of the growth cone but were also seen to move toward a stable Rab11 domain at the growth cone periphery (Fig. 4Aiv; supplemental Movie S5, available at www.jneurosci.org as supplemental material). This suggests that integrins pass through Rab11 domains during recycling at the growth cone but do not remain Rab11-positive for the duration of their transport.

\section{Is $\mathrm{Rab} 11$ required for targeting of $\beta 1$ integrins to the growth cone?}

To test whether an interaction with Rab11 is required for integrins to reach the growth cone, we used siRNA targeting Rab11 (isoforms $\mathrm{A}$ and $\mathrm{B}$ ) to decrease endogenous Rab11 expression. The effectiveness of the fluorescently tagged siRNA was evaluated by Western blotting and densitometry: by $48 \mathrm{~h}$ after transfection, Rab11 expression was decreased by $\sim 80 \%$ (Fig. $5 A$ ) and Rab11 immunofluorescence at the growth cone was reduced to onethird (Fig. 5B). These growth cones had less than one-half the normal level of $\beta 1$ integrin immunofluorescence compared with control transfected cells (Fig. 5B). We validated the target specificity of Rab11 siRNA by stably transfecting cells with an siRNAresistant Rab11-GFP construct, in which three silent mutations had been introduced to the siRNA target region. Rab11 siRNA treatment of Rab11-GFP PC12 cells resulted in an almost complete absence of GFP signal by $2 \mathrm{~d}$ after transfection, whereas siRNA-resistant Rab11-GFP PC12 cells remained fluorescent (supplemental Fig. S5A, available at www.jneurosci.org as supplemental material). Growth cone $\beta 1$ integrin immunofluorescence was reduced when cells expressing normal Rab11-GFP were treated with siRNA, but there was no reduction in siRNAresistant Rab11-GFP PC12 cells (supplemental Fig. S5A, available
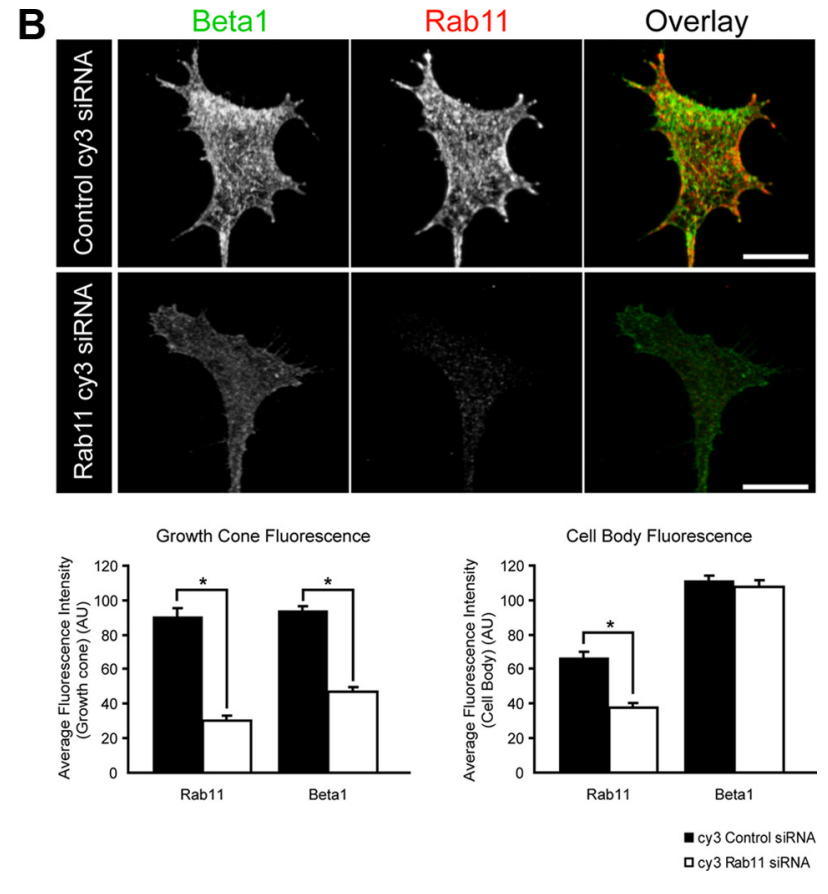

口 cy3 Rab11 siRNA

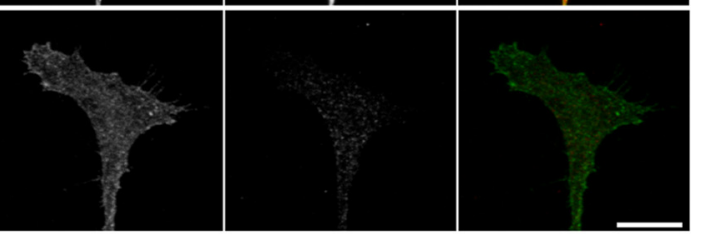

Suppression of endogenous Rab11 by siRNA treatment decreases growth cone integrin levels. Treatment of PC12 cells bars indicate SEM. Scale bar, $10 \mu \mathrm{m}$. See also supplemental Figures S4 and S5 (available at www.jneurosci.org as supplemental

at www.jneurosci.org as supplemental material). The depletion of integrin was only seen in the growth cones; we saw no change in $\beta 1-488$ immunofluorescence at the cell bodies of Rab11depleted cells, finding that $\beta 1$ integrin levels were unaltered (Fig. $5 B$; supplemental Fig. S6 A, available at www.jneurosci.org as supplemental material). This suggests that an interaction with Rab11 is necessary for the targeting of $\beta 1$ integrins to the growth cone.

\section{Is the Rab11 effector Rab coupling protein involved in growth} cone integrin traffic?

Having determined that Rab11 is involved in integrin trafficking in axons and growth cones, we asked whether we could manipulate the Rab11 pathway to increase or decrease integrin expression at the growth cone surface. Previous work has shown that the FIP-family Rab11 effector protein RCP mediates integrin recycling to the plasma membrane (Caswell et al., 2008; Muller et al., 2009). RCP (RAB11FIP1) is ubiquitously expressed in all tissues including brain (Lindsay et al., 2002). As the only available antibodies to RCP do not cross-react with rat, we investigated the protein by generating PC12 cells stably expressing full-length RCP-GFP (Damiani et al., 2004) and a mutant construct that cannot bind to Rab11 and is reported to act as a dominant negative, RCP I621E-GFP (Lindsay and McCaffrey, 2004; Caswell et al., 2008). We generated several cell lines with varying levels of expression and observed similar localization profiles in all. In undifferentiated PC12 cells, RCP exhibited a perinuclear localization and was enriched at the cell periphery and points of protrusion, where it partly overlapped with $\beta 1$ integrins (supplemental Fig. S7, available at www.jneurosci.org as supplemental material). Dominant-negative RCP adopted a more diffuse cytoplasmic distribution and was not enriched at the cell periphery or 

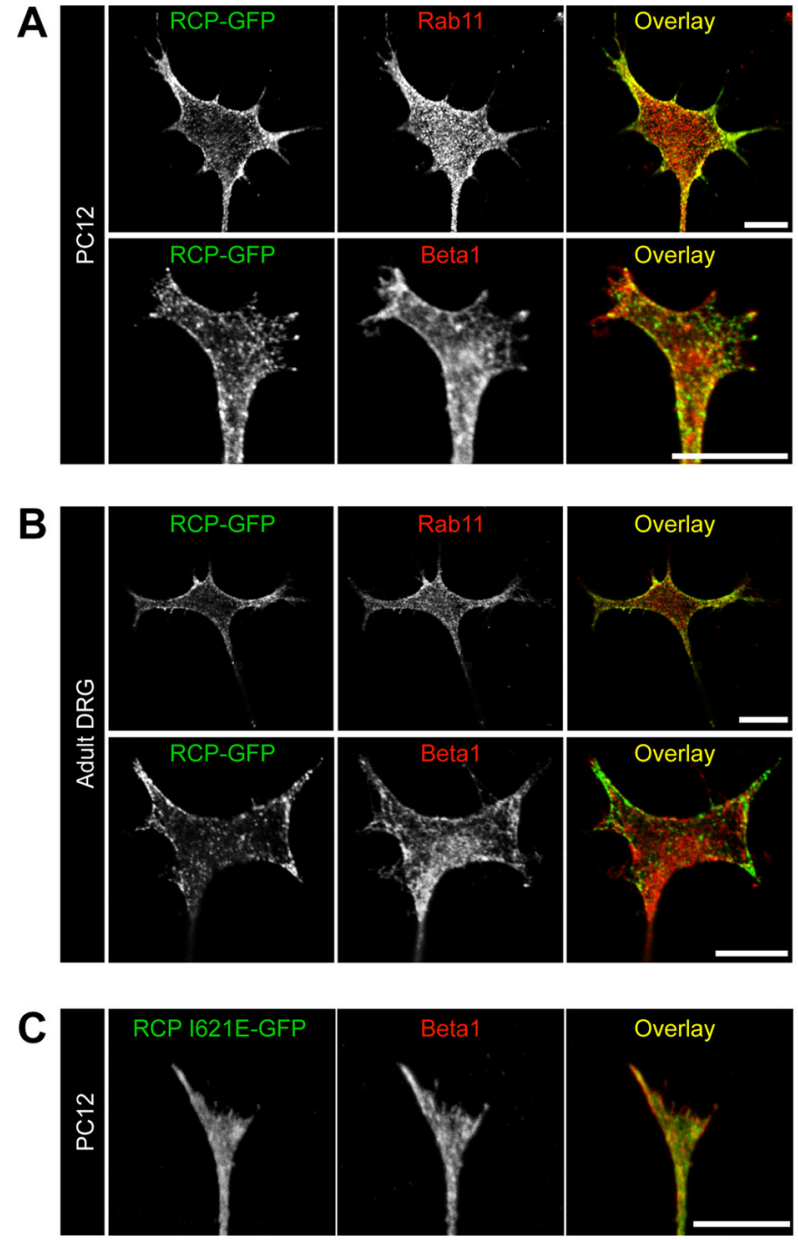

Figure 6. RCP overlaps with $\beta 1$ integrin at the periphery of the growth cone and regulates growth cone morphology. The localization of GFP-tagged RCP constructs was examined in PC12 cells and adult DRG neurons in conjunction with Rab11 or $\beta 1$ integrin localization. In differentiated PC12 cells, RCP-GFP partially overlaps with Rab11 at the growth cone and is enriched at the periphery ( $\boldsymbol{A}$, top panels), where it also overlaps with $\beta 1$ integrin ( $\boldsymbol{A}$, bottom panels). Similar localizations were found in adult DRG growth cones $(\boldsymbol{B})$. Expression of mutant RCP I621E-GFP (that does not bind to Rab11) results in misshapen growth cones $(\boldsymbol{C})$. These growth cones are smaller than control transfected cells $(\boldsymbol{D}$, top graph) $(p<0.05)$ and lack the usual enrichment of integrins at the growth cone periphery (quantified by calculating the ratio of mean peripheral fluorescence vs mean central fluorescence) $(\boldsymbol{D}$, middle graph) $(p<0.001)$. These growth cones also express less $\beta 1$ integrins (surface and intracellular) ( $\boldsymbol{D}$, bottom graph) ( $p<$ 0.01). Images are single confocal sections. Scale bars, $10 \mu \mathrm{m}$. The asterisks $\left(^{*}\right)$ indicate statistical significance using ANOVA followed by post hoc analysis. Error bars indicate SEM. Scale bars, $10 \mu \mathrm{m}$. All images are representative of experiments performed more than three times.

at integrin-rich points of protrusion (supplemental Fig. S7, available at www.jneurosci.org as supplemental material). In primed and differentiated PC12 cells, RCP-GFP partially overlapped with Rab11 at the growth cone, but interestingly RCP was enriched at the growth cone periphery and filopodia (Fig. 6A, top panels), where it localized partly with $\beta 1$ integrins (Fig. $6 A$, bottom panels). We also investigated RCP and endogenous $\beta 1$ integrin localization in adult DRG growth cones and found similar localization profiles. RCP again localizes to the periphery of the growth cone, where it overlaps with Rab11 (Fig. 6B, top panels) and partly with $\beta 1$ integrins (Fig. $6 B$, bottom panels).

PC12 cells stably expressing the non-Rab11 binding RCP I621E mutant protein had small and ill-formed growth cones compared with PC12 cells stably expressing either GFP or RCPGFP (Fig. $6 C, D$, top graph). These growth cones also exhibited abnormally distributed integrins compared with cells expressing the wild-type construct and lacked the usual enrichment of integrins at the growth cone periphery (quantified in Fig. $6 D$, middle
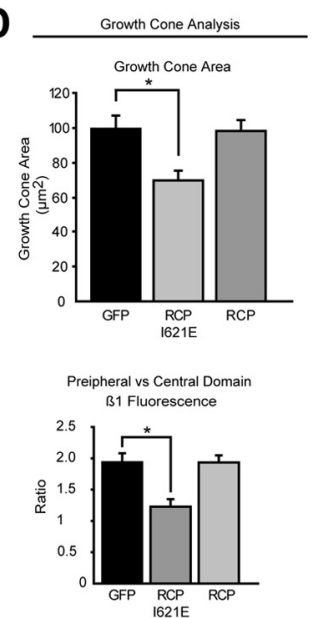

A ratio of 1 represents a uniform distribution.
Higher than1 reresents peripheral enrichment

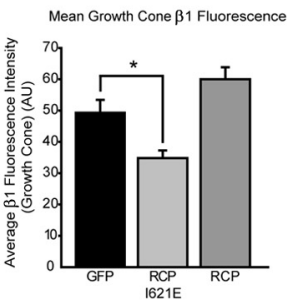

graph). Furthermore, quantification of $\beta 1$ integrins in permeabilized growth cones showed that expression of the RCP I621E mutant protein resulted in a decrease in growth cone integrin levels (Fig. 6D, bottom graph). These data suggest that RCP contributes to the trafficking of $\beta 1$ integrins in PC12 cell growth cones.

\section{Is the Rab11 effector Rab coupling} protein involved in placing $\boldsymbol{\beta} 1$ integrins in the growth cone surface?

We next introduced the RCP constructs into dissociated adult DRG neurons and investigated integrin localization at the growth cone surface using cells that had not been permeabilized. The cells expressing the mutant RCP I621E had very small axonal endings compared with control cells expressing GFP, bearing fewer and shorter filopodia (Fig. 7A,B). Overexpression of RCP-GFP in DRG neurons resulted in larger growth cones compared with the growth cones of control transfected cells (Fig. 7A,B). Within this population of enlarged growth cones, 15\% were strikingly larger than the average control growth cone. These growth cones displayed intense RCP-GFP fluorescence and prominent $\beta 1$ integrin fluorescence when surface labeled with anti $\beta 1-647$. Importantly, we found puncta of RCPGFP coincident with surface-labeled $\beta 1$ integrins on the growth cones of these unpermeabilized DRG neurons (Fig. 7A, bottom panels, arrows), and extensive overlap of signal at the periphery of the growth cone membrane. By quantifying the immunostaining of nonpermeabilized cells, we found that the average fluorescence intensity per unit area of $\beta 1$ integrin on the surface of axon tips of neurons transfected with RCP I621E was unaltered compared with control cells (Fig. 7C), but because of their smaller area the total amount of integrin on the growth cone surface was substantially decreased (Fig. 7C). DRG neurons overexpressing wild-type RCP exhibited substantially higher amounts of $\beta 1$ integrins on their surface compared with control transfected cells and had a greater area, resulting in substantially elevated total integrin levels (Fig. $7 C$ ). We further investigated the effect of RCP overexpression on surface integrin levels using membrane biotinylation followed by NeutrAvidin isolation and Western blotting. DRG neurons do not transfect with a high enough efficiency for biochemical studies, so we used PC12 cells stably expressing GFP (as a control), RCP-GFP or RCP I621E-GFP. Cells expressing RCP I621E-GFP had $34 \%$ less $\beta 1$ integrin on their surface compared with GFP control cells, whereas cells expressing RCP-GFP had 38\% more surface $\beta 1$ integrin compared with controls (Fig. $7 D$ ). These data confirm a role for RCP in regulating $\beta 1$ integrin surface expression in peripheral neurons and suggest that the decrease in growth cone size observed in DRG neurons expressing RCP I621E-GFP may be attributable to a decrease in the total amount 
of $\beta 1$ integrin on the growth cone surface (Fig. 7C). RCP would therefore appear to be involved with Rab11 in directing $\beta 1$ integrins to the growth cone membrane.

\section{Are the effects of RCP on growth cone size attributable to altered integrin expression?}

To determine whether the changes in growth cone size caused by expression of the RCP constructs could be attributed to altered trafficking of integrins, we examined integrin-dependent process growth. We have previously shown that wildtype PC12 cells do not extend neurites on a substrate of tenascin-C, but expression of the tenascin-ligand $\alpha 9$ integrin allows profuse growth, which can be blocked by the $\alpha 9$ integrin blocking antibody (Y9A2) (Andrews et al., 2009). We assayed growth on a tenascin substrate of NGF-treated PC12 cells stably expressing $\alpha 9$ integrin. The cells were transfected with GFP, RCP-GFP, or RCP I621EGFP, and then replated in the presence of NGF for an additional $2 \mathrm{~d}$. To prove that growth is integrin dependent, the cultures were treated acutely (for $30 \mathrm{~min}$ ) with the $\alpha 9$ blocking antibody, Y9A2, using a concentration that generates a partial block of function. We found that $\alpha 9-\mathrm{PC} 12$ cells coexpressing the mutant RCP I621E-GFP had substantially smaller growth cones compared with control cells ( $p<0.001)$, and that addition of the $\alpha 9$ blocking antibody further reduced growth cone size $(p<0.05)$. Interestingly, the neurites of these cells were also marked by the presence of structures resembling retraction bulbs, indicating that the neurites may have been retracting (Fig. $8 A, B$ ). Conversely, coexpression of RCP-GFP resulted in larger growth cones compared with control cells $(p<0.05)$. These growth cones were also more resistant to $\alpha 9$ blockade than control cells (Fig. $8 A, B)$. These data demonstrate that RCP modulates $\alpha 9$ integrin-specific changes to growth cone morphology. Overall, our findings show that RCP influences growth cone morphology via regulation of integrin trafficking.

\section{Does manipulation of Rab11 affect neurite outgrowth?}

To investigate the role of Rab11 in neurite outgrowth, we used siRNA targeting Rab11 (isoforms A and B) as described above. Rab11 interference decreased neurite outgrowth from primed PC12 cells by $25 \%$ (from $250.5 \pm 6.7$ to $186.3 \pm 5.8 \mu \mathrm{m}$; $p<0.001$ by Student's $t$ test) (Fig. 9A; supplemental Fig. S6B, available at www.jneurosci.org as supplemental material). This effect was mirrored in cells stably expressing Rab11-GFP and treated with siRNA but was not observed in cells expressing
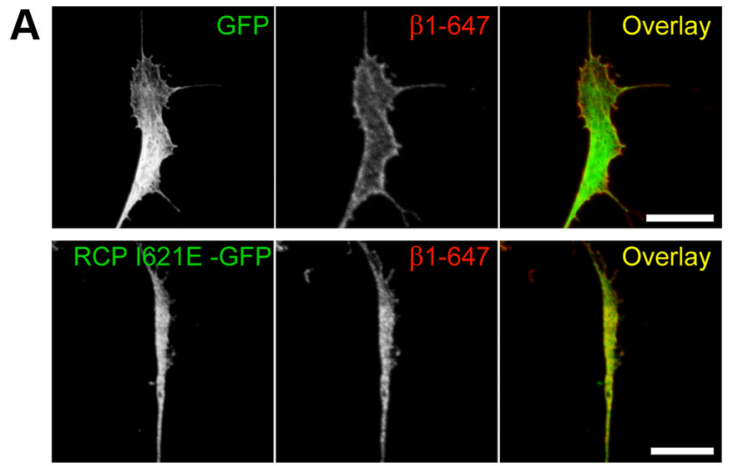

B
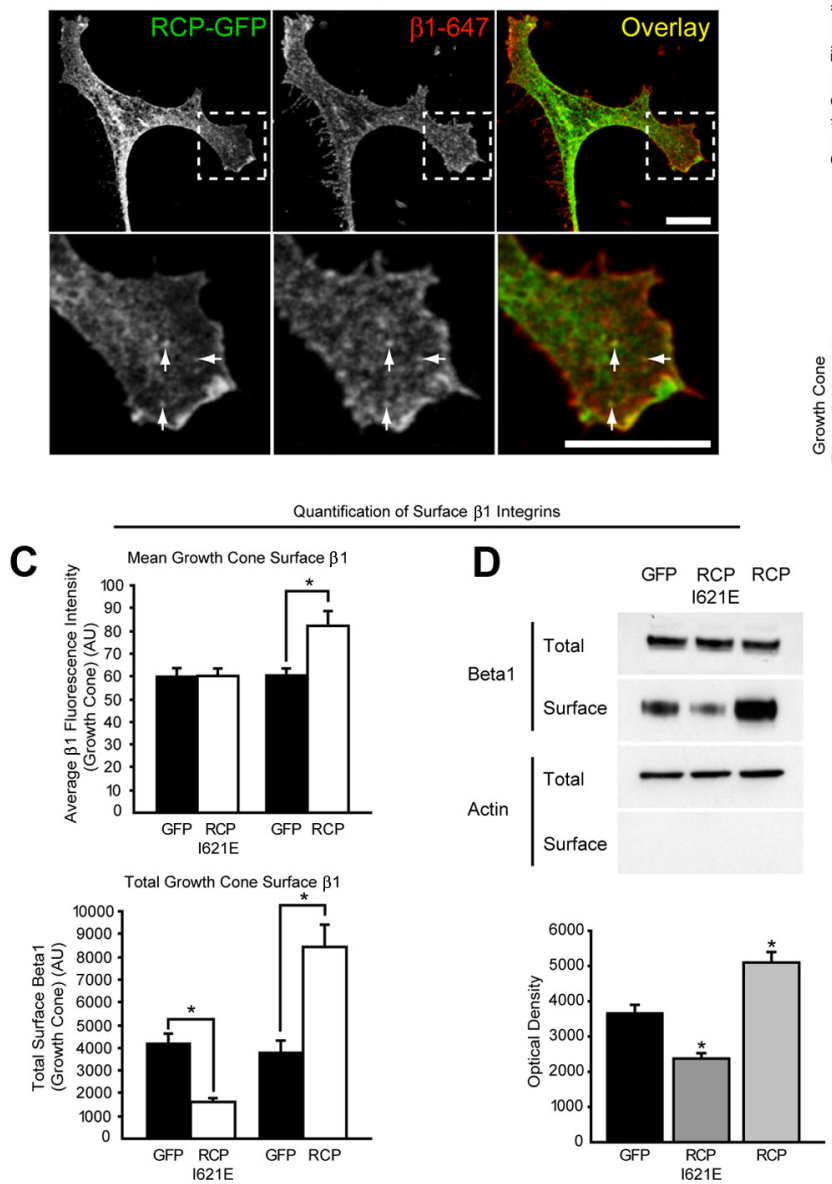

Figure 7. RCP regulates the level of $\beta 1$ integrin on the surface of adult DRG growth cones and differentiated PC12 cells. Expression of RCP-GFP in adult DRG neurons increases growth cone size compared with GFP-transfected controls, whereas expression of mutant RCP I621E-GFP results in smaller growth cones with fewer and shorter filopodia $(\boldsymbol{A}, \boldsymbol{B})$. Intracellular RCP-GFP localizes to the same puncta as surface-labeled $\beta 1$ integrins ( $\boldsymbol{A}$, bottom panels, arrows). Expression of wild-type RCP-GFP increases $\beta 1$ integrin on the surface of adult DRG growth cones, whereas RCP I621E-GFP transfected cells have less $\beta 1$ integrin in total. Analysis of cell surface expression of $\beta 1$ integrin by membrane biotinylation of primed and differentiated stable $\mathrm{PC} 12$ cells (followed by isolation of a membrane fraction using NeutrAvidin beads) confirmed that expression of RCP I621E results in decreased levels of cell surface $\beta 1$ integrin and that elevated RCP expression results in increased surface expression. All images are maximum-intensity projections, except for the bottom-most panel in $A$, which is of a single confocal section. The asterisks $\left(^{*}\right)$ indicate statistical significance using a Student's $t$ test $(\boldsymbol{B}, \boldsymbol{C})$, or ANOVA followed by post hoc analysis $(\boldsymbol{D})(p<0.01)$. Error bars indicate SEM. Scale bars, $10 \mu \mathrm{m}$.
siRNA-resistant Rab11-GFP (supplemental Fig. S5B, available at www.jneurosci.org as supplemental material). We also investigated the effect of Rab11 overexpression in stably transfected PC12 cells with high levels of expression and found that neurite length was increased by $34 \%$ compared with controls $(248.3 \pm$ $4.5 \mu \mathrm{m}$ compared with $184.1 \pm 3.4 \mu \mathrm{m}$, respectively; $p<0.01$ by Student's $t$ test) (Fig. 9A). Expression of Rab11 in adult DRG neurons had a similar but lesser effect, increasing neurite length 

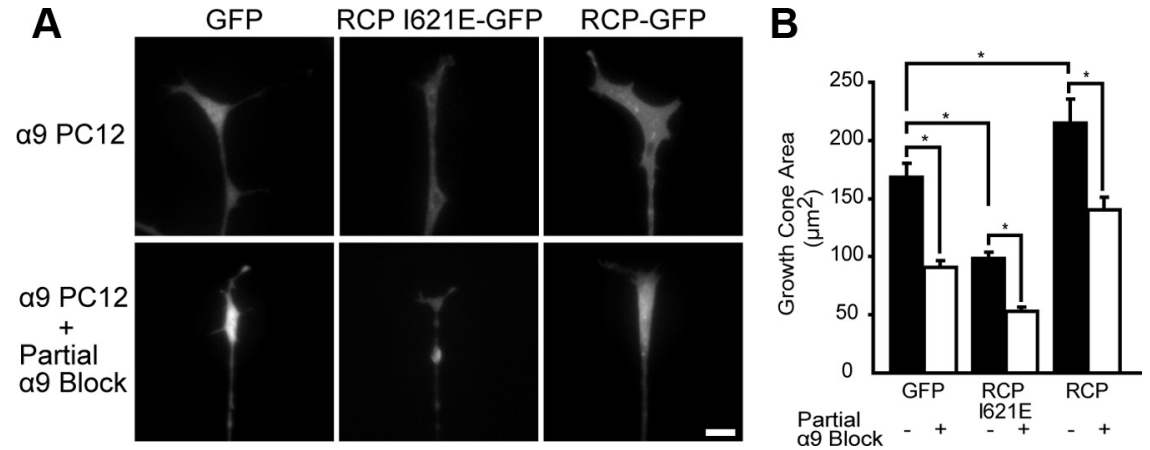

Figure 8. RCP regulates $\alpha 9$ integrin-dependent growth cone morphology. Representative images of PC12 cell growth cones stably expressing $\alpha 9$ integrin, grown on a substrate of tenascin and transfected with RCP-GFP, RCP I621E-GFP, or GFP as control (A). RCP overexpression results in larger growth cones, whereas RCP I621E leads to smaller growth cones compared with controls $(\boldsymbol{A}, \boldsymbol{B})$. Partial antibody blockade of $\alpha 9 \beta 1$ results in smaller growth cones in all cells; however, RCP-expressing cells are diminished to a lesser degree than controls (B). RCP I621E-GFP-expressing cells treated with blocking antibody also exhibit apparent retraction bulbs posterior to the growth cones $(\boldsymbol{A})$. The asterisks $\left.{ }^{*}\right)$ indicate statistical significance using ANOVA followed by post hoc analysis (B) ( $p<0.001$, except for RCP vs GFP, and RCP I621E-GFP vs RCP I621E-GFP with $\alpha 9 \beta 1$ blockade, $p<0.05)$. Error bars indicate SEM. Scale bar, $10 \mu \mathrm{m}$.

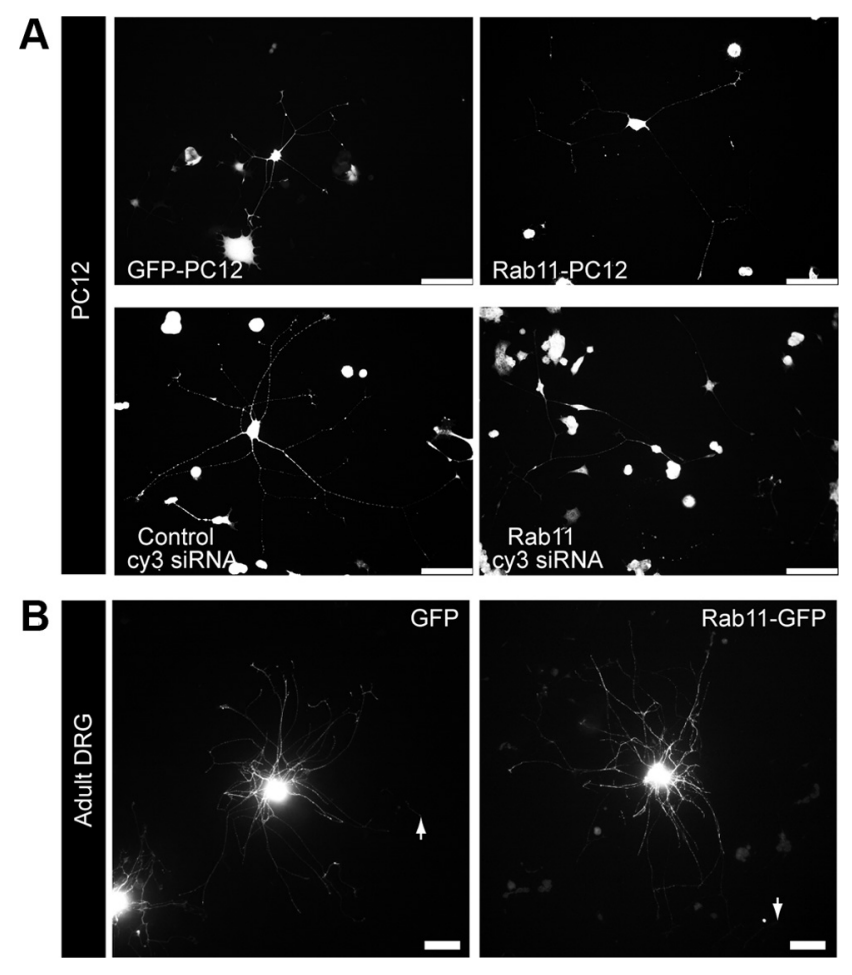

Figure 9. Rab11 regulates neurite outgrowth. Knockdown of Rab11 with siRNA or overexpression of Rab11 alters neurite outgrowth from PC12 cells and adult DRGs. Rab11 Cy3-siRNA transfected cells have shorter neurites compared with control transfected cells $(186.3 \pm 5.8$ $\mu \mathrm{m}$ compared with $250.5 \pm 6.7 \mu \mathrm{m}$, respectively; $p<0.001$ by Student's $t$ test) $(A)$ (see also supplemental Figs. $\$ 5$, S6, available at www.jneurosci.org as supplemental material). Stable expression of Rab11-GFP increases neurite outgrowth from PC12s, compared with control cells stably expressing GFP $(248.3 \pm 4.5 \mu \mathrm{m}$ compared with $184.1 \pm 3.4 \mu \mathrm{m}$, respectively; $p<$ 0.01 by Student's $t$ test) $(\boldsymbol{A})$. Expression of Rab11-GFP also increases neurite outgrowth from adult DRG neurons (from $328.4 \pm 11.5$ to $389.1 \pm 9.7 \mu \mathrm{m} ; p<0.01$ by Student's $t$ test) (B). The arrows indicate the end of the longest axon. Fluorescent signal is GFP. Scale bars, $100 \mu \mathrm{m}$.

by an average of $18.5 \%$ (Fig. 9B). Both Rab11 and control siRNA were toxic to DRG neurons, so we could not test Rab11 knockdown effects. These data suggest that Rab11 is necessary for normal neurite outgrowth and may be a limiting factor in the outgrowth process.

\section{Does manipulation of RCP affect neurite outgrowth?}

We investigated the effects of RCP manipulation on neurite outgrowth using differentiated PC12 cells and adult DRG neurons. RCP-GFP overexpression had no effect on neurite length of stably transfected PC12 cells, but expression of the mutant RCP I621E resulted in a substantial inhibition of neurite length (Fig. 10A, top panels; $B$ ). The effects in adult DRG neurons were the same (Fig. $10 A, C)$. RCP is therefore required for neurite outgrowth.

\section{Does manipulation of the Rab11/RCP pathway affect $\alpha 9$ integrin-specific neurite outgrowth?}

To determine whether Rab11 or RCP can affect neurite outgrowth as a direct result of integrin trafficking, we turned to the $\alpha 9$ integrin-specific outgrowth model and cultured differentiated PC12 cells stably expressing $\alpha 9$ integrin on a substrate of tenascin (as described above regarding Fig. 8). As controls, we used wildtype PC12 cells that do not express $\alpha 9$ integrin. We overexpressed or knocked down Rab11 and examined the effects of expressing either normal or dominant-negative RCP. Wild-type PC12 cells did not extend neurites on tenascin, but $\alpha 9$ integrin PC12 cells extended lengthy neurites that were shorter in the presence of the blocking antibody (again, using a concentration that results in a partial block of function) (Fig. 11A,B). Rab11 overexpression increased neurite outgrowth in $\alpha 9$ integrin PC12 cells, whereas Rab11 siRNA treatment inhibited growth: these results were very similar to the results described earlier from PC12 cells grown on collagen. Overexpression of RCP in $\alpha 9$ integrin PC12 cells resulted in a dramatic increase in neurite outgrowth, whereas expression of RCP I621E-GFP resulted in a substantial inhibition of $\alpha 9$-dependent outgrowth (Fig. 11A,B). Representative images for all of the conditions are presented as supplemental material (supplemental Fig. S8, available at www.jneurosci.org as supplemental material). Together, these data suggest that altering the quantity of Rab11 modulates neurite outgrowth partly as a result of changing integrin levels but also that there is an element of its effect that is integrin independent. However, the effects of RCP or RCP I621E expression on neurite outgrowth appear to be principally attributable to the manipulation of integrin traffic. Our findings suggest that Rab11 and RCP may therefore be useful tools for manipulating the trafficking of transfected and endogenous integrins and for controlling axon growth.

\section{Discussion}

The failure of CNS axons to regenerate after injury has many causes including inhibitory molecules in the CNS environment and the intrinsically low regenerative ability of CNS axons. One of the molecules upregulated at sites of CNS injury is tenascin-C, which is generally inhibitory to axon growth in cells lacking the necessary adhesion molecules to enable growth on tenascin (Joester and Faissner, 2001; Rigato et al., 2002). In a previous study we have shown that expression of the tenascin-binding integrin $\alpha 9$ leads to prolific axon growth in vitro, but modest improvements in growth in the injured spinal cord (Andrews et al., 2009). We reasoned that it will be necessary to develop meth- 
ods to ensure that integrins expressed in neurons reach the cut ends of axons in sufficient quantity to be effective in promoting axon regeneration. We have recently found that $\alpha 9$ integrin is not delivered efficiently into CNS axons in vivo (M. R. Andrews, E. Franssen, E. R. Heintz, and J. W. Fawcett, unpublished findings), and another cell surface molecule, TrkB, overexpressed in vivo in corticospinal axons does not reach the ends of axons at the caudal level of the spinal cord (Hollis et al., 2009). The purpose of this study was to understand the mechanism of integrin trafficking in axons in which integrins are well transported, and to develop tools to manipulate integrin levels in axonal growth cones. Specifically, we aimed to determine whether Rab11 contributes to the trafficking of integrins in peripheral axons and growth cones and, if so, whether this machinery could be manipulated to enhance neurite outgrowth in vitro. We show that $\beta 1$ integrin recycling and trafficking requires Rab11 and the Rab11 effector RCP and that manipulation of these molecules affects growth cone integrin levels and axon growth.

\section{Axonal $\beta 1$ integrins recycle via Rab11} Our initial studies found colocalization of integrins with Rab11 at the growth cones of peripheral neurons. At least some of these integrins have been recycled from the axonal surface, because we find that internalized labeled integrins subsequently localize to Rab11positive structures at both the growth cone and in axons. The association with Rab11 vesicles is necessary to target integrins to the growth cone, because when Rab11 was suppressed, both growth cone integrin levels and axonal growth were reduced. In non-neuronal cells, additional proteins are involved in returning membrane proteins from Rab11 vesicles to the cell surface, with RCP involved in the reinsertion of integrins into the plasma membrane (Caswell et al., 2008; Muller et al., 2009) and the sorting of recycling cargo from a potentially degradative pathway into a recycling pathway (Peden et al., 2004). In axonal growth cones, we demonstrate colocalization of intracellular RCP and surfacelabeled $\beta 1$ integrins. Additionally, we have shown that RCP overexpression increases integrin levels on the growth cone surface, whereas expression of a dominant-negative RCP reduces integrin levels. These findings provide evidence that integrin distribution in axons is regulated by recycling endosomes.

\section{Anterograde transport of integrins}

We asked whether recycling of integrins via Rab11 contributes to their localization and transport in axons. Endocytosed $\beta 1$ integrins associate with Rab11 structures within the axons of DRG neurons. Some cell surface molecules are targeted to axons by first being inserted into the surface membrane of the cell soma, and then endocytosed into recycling endosomes for axonal targeting (Hémar et al., 1997; Sampo et al., 2003; Wisco et al., 2003; Fache et al., 2004; Leterrier et al., 2006; McDonald et al., 2007; Yap et al., 2008a,b), and a recent study has demonstrated that Rab11 is in- volved the anterograde transport of Trk receptors, via a Rab11 compartment (Ascaño et al., 2009). Integrins can be trafficked by a similar mechanism. Using a compartmented culture system, we show that integrins labeled with antibody on DRG cell bodies subsequently appear in puncta transported along axons. However, as this was only observed in some axons, it is possible that newly synthesized integrins may also be directly targeted to the axon. Furthermore, our internalization experiments found that there was always a population of endocytosed integrins within axons that did not label for Rab11. It does not therefore appear that recycling integrins are in Rab11 vesicles for the whole duration of their intracellular transport.

Dynamics of integrins and Rab11 in axons and growth cones Our live-imaging experiments in PC12 neurites revealed that the majority of integrins were in relatively stationary Rab11 compartments but that they could also be found in rapidly moving vesicles that were Rab11 negative. Rab11 only showed short-range bidirectional movement, so it is probable that some rapid anterograde and retrograde transport occurs in a different population of vesicles. This was also evident at the growth cone, as a population of $\alpha 9$-GFP vesicles in the central domain remained Rab11 negative, whereas Rab11-positive integrins were mostly found at the growth cone periphery. In terms of enhancing integrin transport to the growth cone for regenerative purposes, it would be valuable to identify the type of transport vesicle in which rapid transport occurs. It is worthy of note that Rab proteins behave differently in axons compared with non-neuronal cells. For ex- 


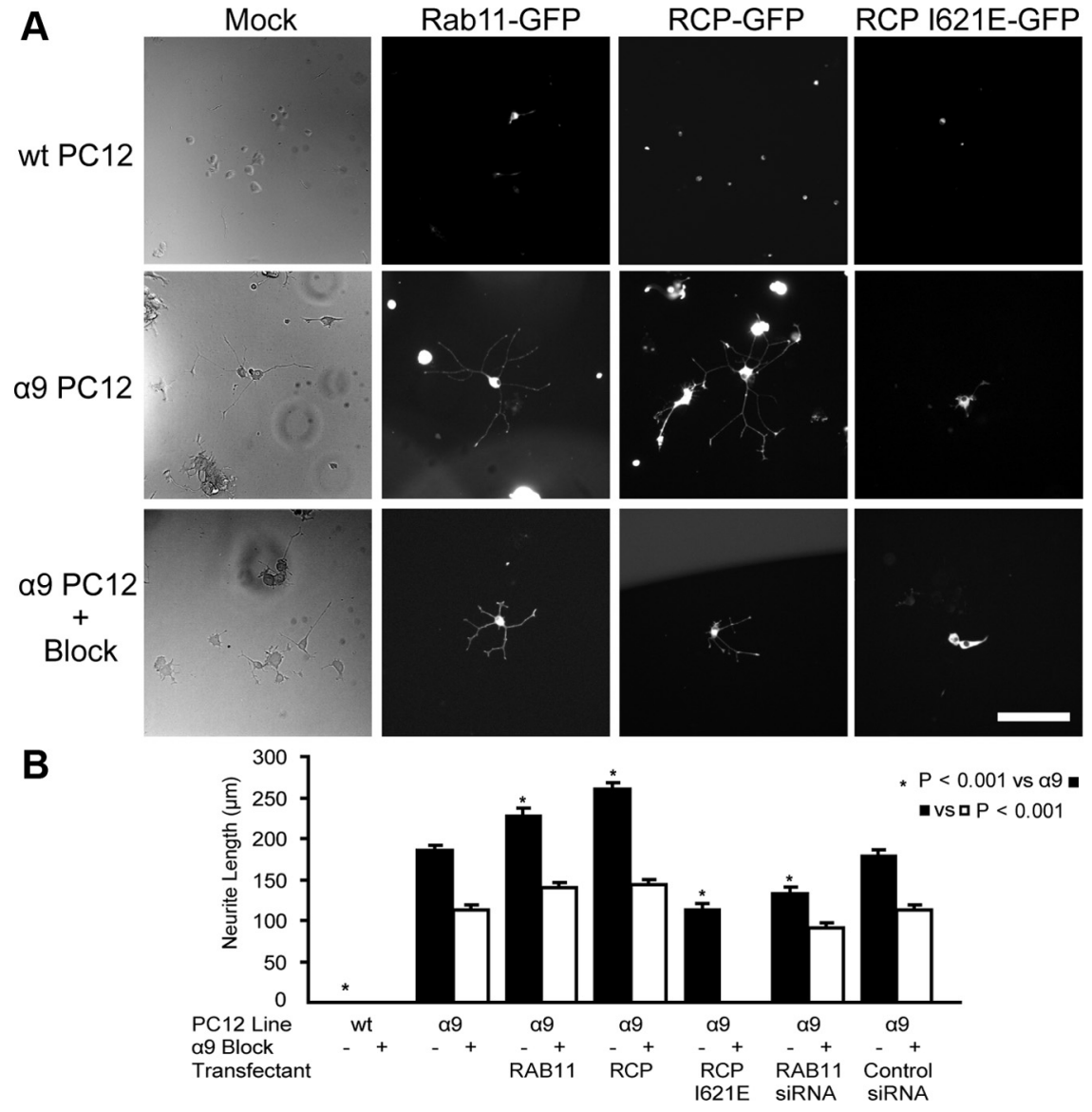

Figure 11. Rab11 and RCP regulate $\alpha 9$ integrin-dependent neurite outgrowth on tenascin. $\boldsymbol{A}$, Representative images of PC12 cells stably expressing $\alpha 9$ integrin and Rab11 or RCP constructs or siRNA. B, Quantification of $\alpha 9$ integrin-dependent neurite outgrowth, as regulated by Rab11 and RCP. PC12 cells stably expressing $\alpha 9$ integrin extend neurites on a substrate of tenascin, whereas wild-type PC12s do not. Growth is inhibited with an $\alpha 9 \beta 1$ blocking antibody. Overexpression of Rab11 increases $\alpha 9$ dependent outgrowth, which is inhibited by anti- $\alpha 9 \beta 1$ (Rab11-GFP column). Overexpression of RCP increases $\alpha 9$-dependent outgrowth to a greater extant than Rab11 and is inhibited by anti- $\alpha 9 \beta 1$ to a similar degree. Expression of RCP I621E inhibits $\alpha 9$-dependent outgrowth and prevents $\alpha 9$-dependent outgrowth in conjunction with anti- $\alpha 9 \beta 1$. Transfection with Rab11 siRNA inhibits $\alpha 9$-dependent outgrowth, and this effect is enhanced by anti- $\alpha 9 \beta 1$. Transfection with control siRNA has no effect on neurite outgrowth. All of the transfectants shown on the graph in $\boldsymbol{B}$ were expressed in both wild-type $\mathrm{PC} 12 \mathrm{~s}$ and $\alpha 9$ integrinexpressing cells, but did not allow for quantifiable outgrowth on wild-type PC12 cells. Expression of Rab11 permitted a very limited amount of outgrowth in a small number of wild-type cells $(\boldsymbol{A})$. Representative images of all conditions are presented as supplemental material (available at www.jneurosci.org as supplemental material). Statistical significance was calculated using ANOVA followed by post hoc analysis $(\boldsymbol{B})$. In all cases, blocking with anti- $\alpha 9 \beta 1$ causes statistically significant changes $(p<0.001)$. Error bars indicate SEM. Scale bar, $250 \mu \mathrm{m}$.

ample, early endosomes marked by Rab5 undergo transport from the cell periphery to the cell body in non-neuronal cells (Rink et al., 2005) but remain relatively static in motoneuron axons, where retrograde axonal transport is achieved by traffic from Rab5- to Rab7-positive structures (Deinhardt et al., 2006).

\section{A role for Rab coupling protein in axonal integrin traffic}

Our results demonstrate a role for RCP in the recycling of integrins within axons. In PC12 cells and adult DRG neurons, we found that GFP-RCP localized with $\beta 1$ integrins at the growth cone periphery, and in DRG neurons on the growth cone surface. We were able to look at RCP function using both gain and loss of function by overexpressing a wild-type RCP and also a mutant that does not bind to Rab11, RCP I621E. The dominant-negative RCP decreased both axonal growth cone integrin levels and axon growth, whereas overexpression of RCP achieved our aim of increasing growth cone integrin levels, but it did not increase axon growth in our in vitro models. Our findings are in keeping with studies in nonneuronal cells, where RCP regulates the recycling of $\alpha 5 \beta 1$ integrins during cell migration (Caswell et al., 2008).

\section{Integrin recycling and neurite outgrowth}

We have shown that reducing growth cone integrin levels through suppression of Rab11 by siRNA or expression of RCPI621E reduced axon growth. In axons growing on collagen or laminin, overexpression of RCP increased growth cone integrin levels and growth cone size, but this had little effect on process growth. However, when we examined $\alpha 9$ integrinspecific outgrowth, we found that RCP overexpression resulted in a substantial increase in outgrowth on a substrate of tenascin. It is also possible that too many integrins at the growth cone could cause excessive adhesion on laminin or collagen, and axon growth does not depend on simple adhesion but requires regulated internalization and recycling of adhesion molecules to create a balance between adhesion and release (Kamiguchi and Lemmon, 2000). However, the study by Caswell et al. (2008) found that RCP-dependent recycling did not affect adhesion but altered migration by coordinating the recycling of $\alpha 5 \beta 1$ integrin with the EGF receptor. If this is the case at the growth cone, excessive integrin might affect this coordination with unfavorable effects for outgrowth (Vaudry et al., 2002; Koprivica et al., 2005). It is also possible that, in our simple culture model using low laminin concentrations, there are already sufficient integrins at the cell surface. More complex integrin trafficking and recycling issues will probably be relevant on other substrates, and particularly in the complex environment of the developing or regenerating CNS, but our data suggest that manipulation of integrin traffic via RCP may be beneficial to neurons transduced with $\alpha 9$ integrin after injury.

In conclusion, our results establish a role for Rab11 and Rab coupling protein in the trafficking of integrins in the axons and growth cones of peripheral neurons. We have shown that manipulation of trafficking pathways and recycling is a method for the control of integrin levels on the surface of axonal growth cones and constitutes a potential strategy for controlling axon outgrowth. Future in vivo experiments will determine whether defective integrin trafficking is involved in the failure of axon regeneration in the damaged CNS and whether manipulation of integrin trafficking is necessary to enable $\alpha 9$ integrin expressed in neurons to reach the growth cones of regenerating axons in sufficient quantity. Our experiments suggest that manipulation of Rab11 and RCP could be a way to solving these potential problems and achieving better axon regeneration. 


\section{References}

Allen J, Chilton JK (2009) The specific targeting of guidance receptors within neurons: who directs the directors? Dev Biol 327:4-11.

Andrews MR, Czvitkovich S, Dassie E, Vogelaar CF, Faissner A, Blits B, Gage FH, ffrench-Constant C, Fawcett JW (2009) $\alpha 9$ integrin promotes neurite outgrowth on tenascin-C and enhances sensory axon regeneration. J Neurosci 29:5546-5557.

Ascaño M, Richmond A, Borden P, Kuruvilla R (2009) Axonal targeting of Trk receptors via transcytosis regulates sensitivity to neurotrophin responses. J Neurosci 29:11674-11685.

Bolte S, Cordelières FP (2006) A guided tour into subcellular colocalization analysis in light microscopy. J Microsc 224:213-232.

Bomsel M, Parton R, Kuznetsov SA, Schroer TA, Gruenberg J (1990) Microtubule- and motor-dependent fusion in vitro between apical and basolateral endocytic vesicles from MDCK cells. Cell 62:719-731.

Brakebusch C, Fässler R (2005) beta 1 integrin function in vivo: adhesion, migration and more. Cancer Metastasis Rev 24:403-411.

Brown TC, Correia SS, Petrok CN, Esteban JA (2007) Functional compartmentalization of endosomal trafficking for the synaptic delivery of AMPA receptors during long-term potentiation. J Neurosci 27:13311-13315.

Caswell PT, Chan M, Lindsay AJ, McCaffrey MW, Boettiger D, Norman JC (2008) Rab-coupling protein coordinates recycling of alpha5betal integrin and EGFR1 to promote cell migration in 3D microenvironments. J Cell Biol 183:143-155.

Choe EA, Liao L, Zhou JY, Cheng D, Duong DM, Jin P, Tsai LH, Peng J (2007) Neuronal morphogenesis is regulated by the interplay between cyclin-dependent kinase 5 and the ubiquitin ligase mind bomb 1. J Neurosci 27:9503-9512.

Cingolani LA, Thalhammer A, Yu LM, Catalano M, Ramos T, Colicos MA, Goda Y (2008) Activity-dependent regulation of synaptic AMPA receptor composition and abundance by beta3 integrins. Neuron 58:749-762.

Correia SS, Bassani S, Brown TC, Lisé MF, Backos DS, El-Husseini A, Passafaro M, Esteban JA (2008) Motor protein-dependent transport of AMPA receptors into spines during long-term potentiation. Nat Neurosci 11:457-466.

Damiani MT, Pavarotti M, Leiva N, Lindsay AJ, McCaffrey MW, Colombo MI (2004) Rab coupling protein associates with phagosomes and regulates recycling from the phagosomal compartment. Traffic 5:785-797.

Deinhardt K, Salinas S, Verastegui C, Watson R, Worth D, Hanrahan S, Bucci C, Schiavo G (2006) Rab5 and Rab7 control endocytic sorting along the axonal retrograde transport pathway. Neuron 52:293-305.

Fabbri M, Di Meglio S, Gagliani MC, Consonni E, Molteni R, Bender JR, Tacchetti C, Pardi R (2005) Dynamic partitioning into lipid rafts controls the endo-exocytic cycle of the alphaL/beta2 integrin, LFA-1, during leukocyte chemotaxis. Mol Biol Cell 16:5793-5803.

Fache MP, Moussif A, Fernandes F, Giraud P, Garrido JJ, Dargent B (2004) Endocytotic elimination and domain-selective tethering constitute a potential mechanism of protein segregation at the axonal initial segment. J Cell Biol 166:571-578.

Gardiner NJ, Fernyhough P, Tomlinson DR, Mayer U, von der Mark H, Streuli CH (2005) Alpha7 integrin mediates neurite outgrowth of distinct populations of adult sensory neurons. Mol Cell Neurosci 28:229-240.

Gardiner NJ, Moffatt S, Fernyhough P, Humphries MJ, Streuli CH, Tomlinson DR (2007) Preconditioning injury-induced neurite outgrowth of adult rat sensory neurons on fibronectin is mediated by mobilisation of axonal alpha5 integrin. Mol Cell Neurosci 35:249-260.

Gorvel JP, Chavrier P, Zerial M, Gruenberg J (1991) rab5 controls early endosome fusion in vitro. Cell 64:915-925.

Hémar A, Olivo JC, Williamson E, Saffrich R, Dotti CG (1997) Dendroaxonal transcytosis of transferrin in cultured hippocampal and sympathetic neurons. J Neurosci 17:9026-9034

Hollis ER 2nd, Jamshidi P, Löw K, Blesch A, Tuszynski MH (2009) Induction of corticospinal regeneration by lentiviral trkB-induced Erk activation. Proc Natl Acad Sci U S A 106:7215-7220.

Hu F, Strittmatter SM (2008) The N-terminal domain of Nogo-A inhibits cell adhesion and axonal outgrowth by an integrin-specific mechanism. J Neurosci 28:1262-1269.

Joester A, Faissner A (2001) The structure and function of tenascins in the nervous system. Matrix Biol 20:13-22.
Kamiguchi H (2003) The mechanism of axon growth: what we have learned from the cell adhesion molecule L1. Mol Neurobiol 28:219-228.

Kamiguchi H, Lemmon V (2000) Recycling of the cell adhesion molecule L1 in axonal growth cones. J Neurosci 20:3676-3686.

Koprivica V, Cho KS, Park JB, Yiu G, Atwal J, Gore B, Kim JA, Lin E, TessierLavigne M, Chen DF, He Z (2005) EGFR activation mediates inhibition of axon regeneration by myelin and chondroitin sulfate proteoglycans. Science 310:106-110.

Laukaitis CM, Webb DJ, Donais K, Horwitz AF (2001) Differential dynamics of alpha 5 integrin, paxillin, and alpha-actinin during formation and disassembly of adhesions in migrating cells. J Cell Biol 153:1427-1440.

Leterrier C, Lainé J, Darmon M, Boudin H, Rossier J, Lenkei Z (2006) Constitutive activation drives compartment-selective endocytosis and axonal targeting of type 1 cannabinoid receptors. J Neurosci 26:3141-3153.

Lindsay AJ, McCaffrey MW (2004) Characterisation of the Rab binding properties of Rab coupling protein (RCP) by site-directed mutagenesis. FEBS Lett 571:86-92.

Lindsay AJ, Hendrick AG, Cantalupo G, Senic-Matuglia F, Goud B, Bucci C, McCaffrey MW (2002) Rab coupling protein (RCP), a novel Rab4 and Rab11 effector protein. J Biol Chem 277:12190-12199.

Lisé MF, Wong TP, Trinh A, Hines RM, Liu L, Kang R, Hines DJ, Lu J, Goldenring JR, Wang YT, El-Husseini A (2006) Involvement of myosin $\mathrm{Vb}$ in glutamate receptor trafficking. J Biol Chem 281:3669-3678.

McDonald NA, Henstridge CM, Connolly CN, Irving AJ (2007) An essential role for constitutive endocytosis, but not activity, in the axonal targeting of the CB1 cannabinoid receptor. Mol Pharmacol 71:976-984.

Milner R, ffrench-Constant C (1994) A developmental analysis of oligodendroglial integrins in primary cells: changes in alpha v-associated beta subunits during differentiation. Development 120:3497-3506.

Moser M, Bauer M, Schmid S, Ruppert R, Schmidt S, Sixt M, Wang HV, Sperandio M, Fässler R (2009) Kindlin-3 is required for beta2 integrinmediated leukocyte adhesion to endothelial cells. Nat Med 15:300-305.

Muller PA, Caswell PT, Doyle B, Iwanicki MP, Tan EH, Karim S, Lukashchuk N, Gillespie DA, Ludwig RL, Gosselin P, Cromer A, Brugge JS, Sansom OJ, Norman JC, Vousden KH (2009) Mutant p53 drives invasion by promoting integrin recycling. Cell 139:1327-1341.

Park M, Penick EC, Edwards JG, Kauer JA, Ehlers MD (2004) Recycling endosomes supply AMPA receptors for LTP. Science 305:1972-1975.

Pazyra-Murphy MF, Segal RA (2008) Preparation and maintenance of dorsal root ganglia neurons in compartmented cultures. J Vis Exp pii:951.

Peden AA, Schonteich E, Chun J, Junutula JR, Scheller RH, Prekeris R (2004) The RCP-Rab11 complex regulates endocytic protein sorting. Mol Biol Cell 15:3530-3541.

Pellinen T, Ivaska J (2006) Integrin traffic. J Cell Sci 119:3723-3731.

Plantman S, Patarroyo M, Fried K, Domogatskaya A, Tryggvason K, Hammarberg H, Cullheim S (2008) Integrin-laminin interactions controlling neurite outgrowth from adult DRG neurons in vitro. Mol Cell Neurosci 39:50-62.

Powelka AM, Sun J, Li J, Gao M, Shaw LM, Sonnenberg A, Hsu VW (2004) Stimulation-dependent recycling of integrin betal regulated by ARF6 and Rab11. Traffic 5:20-36.

Pozzi A, Wary KK, Giancotti FG, Gardner HA (1998) Integrin alphalbeta1 mediates a unique collagen-dependent proliferation pathway in vivo. J Cell Biol 142:587-594.

Rigato F, Garwood J, Calco V, Heck N, Faivre-Sarrailh C, Faissner A (2002) Tenascin-C promotes neurite outgrowth of embryonic hippocampal neurons through the alternatively spliced fibronectin type III BD domains via activation of the cell adhesion molecule F3/contactin. J Neurosci 22:6596-6609.

Rink J, Ghigo E, Kalaidzidis Y, Zerial M (2005) Rab conversion as a mechanism of progression from early to late endosomes. Cell 122:735-749.

Sampo B, Kaech S, Kunz S, Banker G (2003) Two distinct mechanisms target membrane proteins to the axonal surface. Neuron 37:611-624.

Skalski M, Coppolino MG (2005) SNARE-mediated trafficking of alpha5beta1 integrin is required for spreading in $\mathrm{CHO}$ cells. Biochem Biophys Res Commun 335:1199-1210.

Sönnichsen B, De Renzis S, Nielsen E, Rietdorf J, Zerial M (2000) Distinct membrane domains on endosomes in the recycling pathway visualized by multicolor imaging of Rab4, Rab5, and Rab11. J Cell Biol 149:901-914.

Ullrich O, Reinsch S, Urbé S, Zerial M, Parton RG (1996) Rab11 regulates 
recycling through the pericentriolar recycling endosome. J Cell Biol 135:913-924.

Vaudry D, Stork PJ, Lazarovici P, Eiden LE (2002) Signaling pathways for PC12 cell differentiation: making the right connections. Science 296: $1648-1649$.

Wang Z, Edwards JG, Riley N, Provance DW Jr, Karcher R, Li XD, Davison IG, Ikebe M, Mercer JA, Kauer JA, Ehlers MD (2008) Myosin Vb mobilizes recycling endosomes and AMPA receptors for postsynaptic plasticity. Cell 135:535-548.

Webb DJ, Zhang H, Majumdar D, Horwitz AF (2007) alpha5 integrin signaling regulates the formation of spines and synapses in hippocampal neurons. J Biol Chem 282:6929-6935.

Werner A, Willem M, Jones LL, Kreutzberg GW, Mayer U, Raivich G (2000) Impaired axonal regeneration in $\alpha 7$ integrin-deficient mice. J Neurosci $20: 1822-1830$.
Winckler B (2004) Scientiae forum/models and speculations pathways for axonal targeting of membrane proteins. Biol Cell 96:669-674.

Wisco D, Anderson ED, Chang MC, Norden C, Boiko T, Fölsch H, Winckler B (2003) Uncovering multiple axonal targeting pathways in hippocampal neurons. J Cell Biol 162:1317-1328.

Yap CC, Wisco D, Kujala P, Lasiecka ZM, Cannon JT, Chang MC, Hirling H, Klumperman J, Winckler B (2008a) The somatodendritic endosomal regulator NEEP21 facilitates axonal targeting of L1/NgCAM. J Cell Biol 180:827-842.

Yap CC, Nokes RL, Wisco D, Anderson E, Fölsch H, Winckler B (2008b) Pathway selection to the axon depends on multiple targeting signals in NgCAM. J Cell Sci 121:1514-1525.

Yoon SO, Shin S, Mercurio AM (2005) Hypoxia stimulates carcinoma invasion by stabilizing microtubules and promoting the Rab11 trafficking of the alpha6beta4 integrin. Cancer Res 65:2761-2769. 